\title{
Beyond the carapace: skull shape variation and morphological systematics of long-nosed armadillos (genus Dasypus)
}

\author{
Lionel Hautier ${ }^{\text {Corresp., }}{ }^{1,2}{ }^{\text {, Guillaume Billet }}{ }^{3}$, Benoit De Thoisy ${ }^{4,5}$, Frédéric Delsuc ${ }^{6}$ \\ 1 Institut des Sciences de l'Evolution, UMR5554, CNRS, IRD, EPHE, Université de Montpellier, Montpellier, France \\ 2 Mammal Section, Life Sciences, Vertebrate Division, The Natural History Museum, London, United Kingdom \\ 3 Museum National d'Histoire Naturelle, CR2P, UMR 7207, CNRS, Université Paris 6, Paris, France \\ 4 Institut Pasteur de la Guyane, Cayenne, France \\ 5 Kwata NGO, Cayenne, France \\ 6 Institut des Sciences de l'Evolution, UMR 5554, CNRS, IRD, EPHE, Université de Montpellier, Montpellier, France \\ Corresponding Author: Lionel Hautier \\ Email address: lionel.hautier@umontpellier.fr
}

Background. The systematics of long-nosed armadillos (genus Dasypus) has been mainly based on a handful of external morphological characters and classical measurements. Here, we studied the pattern of morphological variation in the skull of long-nosed armadillos species, with a focus on the systematics of the widely distributed nine-banded armadillo (D. novemcinctus). Methods. We present the first exhaustive 3D comparison of the skull morphology within the genus Dasypus, based on $\mu \mathrm{CT}$-scans. We used geometric morphometric approaches to explore the patterns of the intra- and interspecific morphological variation of the skull with regard to several factors such as taxonomy, geography, allometry, and sexual dimorphism. Results. We show that the shape and size of the skull vary greatly among Dasypus species, with $D$. pilosus representing a clear outlier compared to other long-nosed armadillos. The study of the cranial intraspecific variation in $D$. novemcinctus evidences clear links to the geographic distribution and argues in favour of a revision of past taxonomic delimitations. Our detailed morphometric comparisons detected previously overlooked morphotypes of nine-banded armadillos, especially a very distinctive unit restricted to the Guiana Shield. Discussion. As our results are congruent with recent molecular data and analyses of the structure of paranasal sinuses, we propose that $D$. novemcinctus should be regarded either as a polytypic species (with three to four subspecies) or as a complex of several distinct species. 


\section{Beyond the carapace: skull shape variation and morphological systematics of}

\section{2 long-nosed armadillos (genus Dasypus).}

3

4 Lionel Hautier ${ }^{1,2}$, Guillaume Billet ${ }^{3}$, Benoit de Thoisy ${ }^{4,5}$, and Frédéric Delsuc ${ }^{1}$

5

$6{ }^{1}$ Institut des Sciences de l'Evolution, UMR5554, CNRS, IRD, EPHE, Université de Montpellier,

7 Montpellier, France.

8 2Mammal Section, Life Sciences, Vertebrate Division, The Natural History Museum, London, 9 UK.

10 3Sorbonne Universités, CR2P, UMR 7207, CNRS, Université Paris 6, Muséum National

11 d'Histoire Naturelle, Paris, France.

$12{ }^{4}$ Institut Pasteur de la Guyane, Cayenne, France.

$13{ }^{5}$ Kwata NGO, Cayenne, France.

16 Corresponding Author

17 Lionel Hautier

18 Email address: lionel.hautier@,umontpellier.fr. 


\section{Abstract}

20 Background. The systematics of long-nosed armadillos (genus Dasypus) has been mainly based 21 on a handful of external morphological characters and classical measurements. Here, we studied

22 the pattern of morphological variation in the skull of long-nosed armadillos species, with a focus 23 on the systematics of the widely distributed nine-banded armadillo (D. novemcinctus).

24 Methods. We present the first exhaustive 3D comparison of the skull morphology within the 25 genus Dasypus, based on $\mu \mathrm{CT}$-scans. We used geometric morphometric approaches to explore

26 the patterns of the intra- and interspecific morphological variation of the skull with regard to

27 several factors such as taxonomy, geography, allometry, and sexual dimorphism.

28 Results. We show that the shape and size of the skull vary greatly among Dasypus species, with D. pilosus representing a clear outlier compared to other long-nosed armadillos. The study of the 30 cranial intraspecific variation in D. novemcinctus evidences clear links to the geographic

31 distribution and argues in favour of a revision of past taxonomic delimitations. Our detailed

32 morphometric comparisons detected previously overlooked morphotypes of nine-banded

33 armadillos, especially a very distinctive unit restricted to the Guiana Shield.

34 Discussion. As our results are congruent with recent molecular data and analyses of the structure 35 of paranasal sinuses, we propose that $D$. novemcinctus should be regarded either as a polytypic 36 species (with three to four subspecies) or as a complex of several distinct species. 


\section{Introduction}

38 With their Pan-American distribution, long-nosed armadillos (genus Dasypus) constitute an

39 understudied model for Neotropical biogeography. They are the most taxonomically diverse and

40 widespread extant xenarthrans. The genus Dasypus traditionally comprises seven extant species

41 (D. novemcinctus, D. hybridus, D. septemcinctus, D. kappleri, D. pilosus, D. mazzai, and D.

42 sabanicola; Wetzel, 1985; Wilson \& Reeder, 2005; Feijo \& Cordeiro-Estrela, 2014) and two

43 extinct ones (D. bellus and D. punctatus; Castro et al., 2013; Castro, 2015). In spite of being one

44 of the earliest diverging cingulate lineages (Gaudin \& Wible, 2006; Delsuc et al., 2012; Gibb et

45 al., 2016), the early evolutionary history of dasypodines remains poorly known (Castro, 2015).

46 Only three extinct genera are currently recognized among the Dasypodini: Anadasypus from the

47 middle Miocene of Colombia and late Miocene of Ecuador (Carlini, Vizcaíno \& Scillato-yané,

48 1997; Carlini et al., 2013), Pliodasypus from the late Pliocene of Venezuela (Castro et al., 2014),

49 and Propraopus from the middle Pleistocene-early Holocene of South America (Castro et al.,

50 2013a).

Aside from the widespread nine-banded armadillo (D. novemcinctus), all extant long-

52 nosed armadillos are restricted to South America. Some species are sympatric in certain areas,

53 resulting in competition and possibly supporting divergent behaviours and morphologies. The

54 nine-banded armadillo is likely to be the most abundant armadillo in tropical forests (Wetzel \&

55 Mondolfi, 1979; Loughry \& McDonough, 1998), and it has the widest distribution of all extant

56 xenarthran species. Its distribution is thought to cover much of South and Central America and

57 parts of North America, and it ranges from the southeastern United States to northwestern

58 Argentina and Uruguay (McBee \& Baker, 1982; Loughry \& McDonough, 2013). The species

59 ability to disperse quickly, as well as its opportunistic and generalist mode of life, could partly 
60 explain this broad distribution (Smith \& Doughty, 1984; Loughry \& McDonough, 1998, 2013) as

61 well as its rapid historical expansion into the United States (Taulman \& Robbins, 2014). Such a

62 wide geographical distribution, combined with long-recognized morphological variations (Peters,

63 1864; Gray, 1873; Allen, 1911; Lönnberg, 1913; Russell, 1953), raise the possibility that major

64 taxonomic subgroups have been overlooked, be it at the subspecific or even specific level.

65 As its vernacular name implies, the genus Dasypus is characterized by a long, slender

66 rostrum, which represents at least 55\% of the length of the head (Gardner, 2008). The different

67 species are usually distinguished by body and cranial measurements, colour differences, and

68 morphological features of the carapace, such as the number of movable bands and scutes across

69 the body and the number and shape of osteodermal foramina (Wetzel, 1985; Feijo \& Cordeiro-

70 Estrela, 2016). The carapace is a hallmark of armadillos, and constitutes such a unique feature

71 for mammals that it has dominated the attention of early and modern anatomists and, as a result,

72 partly jeopardized the classification of the group. Its morphology, chiefly the number of movable

73 bands, has been extensively used in systematic studies. However, even in the so-called nine-

74 banded armadillo, the number of movable bands can vary from 7 to 11 (Wetzel \& Mondolfi, 1979;

75 McBee \& Baker, 1982). Yet early on, in his Systema Naturae, Linnaeus (1758:51) cast doubt on

76 the usefulness of the number of movable bands as a criterion to distinguish Dasypus species (in

77 this case $D$. septemcinctus from $D$. novemcinctus). Since then, a number of authors have raised

78 the question whether such external features could be confidently used for systematic purposes.

79 Wetzel and Mondolfi (1979:46) argued that "although many scientific names of armadillos are

80 based on the number of movable bands, it is proposed here that for vernacular names we

81 discontinue using this variable characteristic and base names upon unique or more consistent

82 features." In the early $20^{\text {th }}$ century, Hamlett (1939) made similar observations on the nine-banded 
83 armadillo. He considered it impossible to recognize external variations at a subspecific level, and

84 concluded that "cranial characters appear to offer the only promise for subspecific analysis of the

85 species" (Hamlett 1939:335). We decided to further investigate Hamlett's idea, since no large

86 review of the dasypodine cranial variation has been undertaken to date.

87 This study aims to further elucidate the pattern of morphological variation seen in the

88 skull of long-nosed armadillos, with a focus on the nine-banded armadillo. Geometric

89 morphometric data were collected for most Dasypus species using $\mu \mathrm{CT}$-scans. The main

90 questions asked in the present study are whether different patterns of variation in skull shape can

91 be characterized among and within long-nosed armadillo species, and if those patterns could be

92 linked to factors such as taxonomy, geographical distribution, skull size, or sexual dimorphism.

93 Our ultimate goals are to reconstruct the details of the biogeographic distribution of the

94 widespread nine-banded armadillo at the continental scale and to lay the path for a new

95 integrative taxonomy of long-nosed armadillos. A greater understanding of the morphological

96 diversity and patterns of evolution for long-nosed armadillos is timely to effectively conserve

97 these species, and will also serve to deepen our knowledge of their peculiar evolution and

98 biology (Loughry \& McDonough, 2013).

100 Materials \& Methods

101 Biological samples

102 The material studied came from the collections of the Muséum national d'Histoire naturelle

103 (MNHN, collections Zoologie et Anatomie comparée, Mammifères et Oiseaux) in Paris (France),

104 the Natural History Museum (BMNH) in London (UK), the Naturalis Biodiversity Center (NBC)

105 in Leiden (Holland), the Royal Ontario Museum (ROM) in Toronto (Canada), the Museum of 
106 Natural Science of the Louisiana State University (LSU) in Bâton-Rouge (USA), the American

107 Museum of Natural History (AMNH) in New York (USA), the National Museum of Natural

108 History (NMNH) in Washington (USA), the Instituto de Pesquisas Científicas e Tecnológicas do

109 Estado do Amapá (IEPA) in Macapá (Brazil), and the Muséum d'Histoire Naturelle in Geneva

110 (Switzerland), the KWATA association in Cayenne (French Guiana), and the personal collection

111 of Pierre Charles-Dominique in Montpellier (France). We analysed 128 skulls belonging to five

112 Dasypus species (see Table S1 for a complete list of specimens): D. novemcinctus, D. hybridus,

113 D. septemcinctus, D. kappleri, and D. pilosus (no data was available for D. mazzai, and D.

114 sabanicola). With these data we performed a preliminary assessment of the average amounts of

115 cranial variation at the specific level among different populations of $D$. novemcinctus from

116 French Guiana, Guyana, Suriname, Ecuador, Brazil, Venezuela, Colombia, Costa Rica, Belize,

117 Bolivia, Argentina, Paraguay, Uruguay, Panama, Nicaragua, Honduras, Guatemala, Mexico,

118 Peru, and the USA (Table S1). Juvenile, subadult, and adult specimens were considered in order

119 to take into account the effect of age, size, and differential growth on the dataset. Several studies

120 (Hensel, 1872; Russell, 1953; Ciancio et al., 2012) showed that long-nosed armadillos possess

121 tooth replacement, as is typical for mammals, and that the eruption of permanent teeth occurs

122 relatively late, as observed in afrotherians (Asher \& Lehmann, 2008). Accordingly, we used

123 eruption of the teeth, suture closure, and size (i.e., skull length) as criteria to identify adult

124 specimens in our dataset. Specimens were considered as juveniles when they displayed milk

125 teeth and an open suture between the basioccipital and the basisphenoid. Subadults were

126 characterized by erupting permanent teeth. Adult specimens always showed a closed

127 basioccipital/basisphenoid suture and a fully erupted permanent dentition. Except when

128 specified, only adults and subadults specimens were considered in the morphometrical analyses. 


\section{Geometric morphometric methods}

131 Due to the limitations of the classical qualitative descriptive approach, geometric morphometrics

132 represents a good complementary technique by which to examine intraspecific shape variation.

133 Digital data for all specimens were acquired using X-ray micro-computed tomography $(\mu \mathrm{CT})$ at

134 the University of Montpellier (France), at the Natural History Museum (London, UK), and at the

135 AST-RX platform MNHN (Paris, France). Three-dimensional reconstruction and visualization of

136 the skulls were performed using stacks of digital $\mu \mathrm{CT}$ images with AVIZO v. 6.1.1 software

137 (Visualization Sciences Group 2009). The mandibles and crania of armadillos were quantified

138 with 10 and 84 anatomical landmarks respectively (Fig. 1 and Tables 1 and 2) using ISE-

139 MeshTools (version 1.3.1; Lebrun, 2014). These landmarks were inspired by previous studies

140 performed on different mammalian taxa (Hautier, Lebrun \& Cox, 2012; Hautier et al., 2014).

141 Considering the tendency toward the reduction of the number of teeth in Dasypus (Allen, 1911),

142 specimens often lack the last dental locus, which corresponds to a molar (Ciancio et al., 2012). In

143 order to avoid producing an artificial shortening of the entire tooth row, we decided not to place

144 a landmark at the end of the tooth row, as it is commonly the case, but after the last premolar

145 locus (in both mandible and maxilla). Since skulls were often incomplete, the number of

146 landmarks was adjusted to incorporate the maximal morphological variation in a maximum

147 number of individuals. This number differed when we performed analyses including all Dasypus

148 species (10 and 70 landmarks for the mandible and the cranium respectively) or only $D$.

149 novemcinctus (10 and 82 landmarks for the mandible and the cranium respectively).

150 All configurations (sets of landmarks) were superimposed using the Procrustes method of

151 generalized leastsquares superimposition (GLS scaled, translated, and rotated configurations so 
152 that the intralandmark distances were minimized) following the methods of Rohlf (1999) and

153 Bookstein (1991). Subsequently, mandibular and cranial forms of each specimen were

154 represented by centroid size S, and by multidimensional shape vector $\mathrm{v}$ in linearized Procrustes

155 shape space. Shape variability of the skull and the mandible was analysed by Principal

156 Component Analysis (PCA) of shape (Dryden \& Mardia, 1998). Analysis and visualization of

157 patterns of shape variation were performed with the interactive software package

158 MORPHOTOOLS (Specht, 2007; Specht, Lebrun \& Zollikofer, 2007; Lebrun, 2008; Lebrun et

159 al., 2010).

160 To account for the potentially confounding effects of size allometry on shape of the

161 cranium and mandible at the intraspecific level (i.e., within D. novemcinctus), size-corrected

162 shapes were obtained as follows: we conducted a multivariate regression of Procrustes residuals

163 on the logarithm of the centroid size, yielding an allometric shape vector (ASV). The allometric

164 shape vector represents a direction in shape space, which characterizes mandibular and cranial

165 allometric patterns. All crania and mandibles of $D$. novemcinctus were then projected on

166 allometric shape vectors, the residuals representing the component of skull shape that is

167 independent of size. Shape variation independent of size was analyzed by PCA of shape using

168 MORPHOTOOLS. PCres corresponds to principal components of a PCA performed on shape

169 data corrected for allometry. The same analyses could not be performed at the interspecific level

170 due to large differences in sample size.

171 Multivariate analyses of variance (MANOVA) were performed on the principal component

172 scores of mandibular and cranial mean shapes in order to assess the effects of different factors on

173 mandibular and cranial shape variation: clades (species), sex, and geographic distribution

174 (countries). Because our dataset consisted of a relatively large number of variables, the shape 
175 space was simplified to the first Principal Components (the number of PCs was defined in order

176 to keep $90 \%$ of the interspecific shape variance). MANOVAs were performed with Past 2.06

177 (Hammer, Harper \& Ryan, 2001). Linear discriminant analyses (LDA) of shape coordinates were

178 performed on the same number of PCs to assess a potential discrimination of skull morphology

179 in relation to phylogeny (i.e., species) and geography (i.e., countries). If lumping specimens by

180 country has little biological relevance, we consider that using such artificial boundaries also

181 constitutes a mean to avoid making a priori hypotheses. In all cases, all LDA results were

182 double-checked with post hoc classification methods and PCA results. When a group included

183 only one individual, this specimen was integrated into the dataset as an ungrouped case. A skull

184 from Panama (NMNH 171052) was not complete enough to be considered in these analyses. We

185 then decided to perform similar analyses with a reduced set of landmarks (81 landmarks on the

186 cranium) to enable its morphological comparison with other specimens.

\section{Linear measurements}

189 Several linear measurements of the skull of Dasypus were calculated directly on 3D coordinates

190 of landmarks (Fig. 2). These measurements were used to compare our results with traditional

191 methods of species delineation.

192

\section{Results}

194 Interspecific variation of skull shape among long-nosed armadillos

195 A MANOVA performed on the first 35 PCs (i.e. $90 \%$ of the variance) indicates a significant

196 morphological differentiation of the mandibles and crania relative to species delimitations

197 (mandible Wilks' lambda $=0.01164, \mathrm{~F}=4.903, \mathrm{p}<0.001$; cranium Wilks' lambda $=0.0005897$, 
$198 \mathrm{~F}=11, \mathrm{p}<0.001)$. A multivariate regression of the shape component on size, estimated by the

199 logarithm of centroid size, was significant for the skull (mandible Wilks' lambda=0.2709,

$200 \mathrm{~F}=6.637, \mathrm{p}<0.001 ;$ cranium Wilks' lambda=0.0632, $\mathrm{F}=30.92, \mathrm{p}<0.001)$.

201 Morphological differences occur among the mandibles of the five species of Dasypus

202 (Fig. 3A). The first two principal components (24.73\% and $16.48 \%$ of total shape variation)

203 weakly discriminates D. pilosus (negative values) from D. kappleri (positive values) while all

204 specimens of $D$. novemcinctus, D. hybridus, and D. septemcinctus sit in the middle of the graph.

205 These axes separate mandibles having a slender horizontal ramus, an elongated anterior part

206 (located in front of the tooth row), a short ascending ramus, and a short, anteriorly positioned and

207 vertically oriented coronoid process, from mandibles showing a high horizontal ramus, a short

208 anterior region, a long ascending ramus, and an elongated and distally oriented coronoid process.

209 Mandibles of different size are poorly discriminated along the first principal component (Fig.

$2103 \mathrm{~B})$.

211 The interspecific differences in the cranium of Dasypus are apparent in the morphospace

212 defined by the first two principal components. Except for D. hybridus and D. septemcinctus, all

213 species are well discriminated in the morphospace defined by the two first principal components

214 (Fig. 4A), which explain 28.76\% and 15.29\% of the variance respectively. The first principal

215 component unequivocally discriminates $D$. hybridus and $D$. septemcinctus from other species,

216 and negatively correlates with a shortened rostrum and enlarged basicranium and braincase (Fig.

217 4A). D. pilosus individuals are well discriminated on the second principal component. On PC2

218 (Fig. 4A), the crania of D. pilosus appear narrower, with a long snout and smaller braincase

219 (positive values), whereas the crania of D. novemcinctus, D. kappleri, D. hybridus, and D.

220 septemcinctus are wider, with a shorter snout and relatively small braincase (negative values). A 
221 regression of the first principal component on the logarithm of the centroid size (Fig. 4B) clearly

222 shows that the five species show different size ranges. The biggest crania are long and display a

223 longer and wider snout, whereas the smallest crania are short and wide posteriorly and

224 characterized by a short snout. A posteriori classification methods produced $100 \%$ correct

225 specific classification of specimens.

226 We also performed the same analyses, this time including juvenile specimens (Figure S2)

227 but excluding D. pilosus, since it represents a clear outlier in the morphospace. All juvenile

228 specimens of $D$. novemcinctus tend to exhibit negative values for $\mathrm{PC} 1$, and thus appear more

229 similar in shape to D. septemcinctus and D. hybridus than the adult D. novemcinctus. All

230 juveniles of $D$. novemcinctus and $D$. septemcinctus exhibit more negative values of PC1 and

231 more positive values of PC2 relative to the adult individuals of their own species. Such a

232 distribution in the morphospace defined by PC1-2 suggests similar ontogenetic trajectories for

233 the two species.

234

235

Intraspecific variation of skull shape in nine-banded armadillos

236 In specimens for which sex was available (22 females and 32 males for the mandible; 19 females

237 and 34 males for the cranium), a MANOVA shows that there is no sexual dimorphism present in

238 the cranial data (Wilks' lambda $=0.2429, \mathrm{~F}=1.514, \mathrm{p}=0.182$ ), so sex is unlikely to be responsible

239 for the variation observed in the cranium of $D$. novemcinctus, although it might partly account

240 for the variation in the mandible (Wilks' lambda=0.2292, $\mathrm{F}=2.579, \mathrm{p}=0.011$ ). ANOVAs also

241 show that there is no relationship between sex and size (mandibles, $\mathrm{F}=0.4219$, $\mathrm{p}=0.52$; crania,

$242 \mathrm{~F}=0.00143, \mathrm{p}=0.97)$. A multivariate regression of the shape component on size was significant

243 (mandible, Wilks' lambda=0.3468, $\mathrm{F}=3.454, \mathrm{p}<0.001$; cranium, Wilks' lambda=0.1447, 
$244 \mathrm{~F}=8.446, \mathrm{p}<0.001)$. When looking at the allometric shape vectors obtained with the centroid size

245 (Figure S1), we found that size explains $14.14 \%$ and $14.32 \%$ of the variation in the whole

246 mandibular and cranial data sets respectively. Shape data corrected for allometry are presented in

247 Figures S3 and S4.

248 A weak intraspecific differentiation (per country) is noticeable in the mandibular

249 morphology data (Wilks' lambda $=0.0001404, \mathrm{~F}=1.523, \mathrm{p}<0.001$; Fig. 5A). The first principal

250 component (9.87\% of total shape variation) weakly discriminates specimens from Brazil,

251 Bolivia, Paraguay, Uruguay (positive values) from other specimens (negative values). This axis

252 separates mandibles characterized by a robust and short horizontal ramus, a long ascending

253 ramus, a high coronoid process, a low condylar process, and a poorly individualized angular

254 process, from mandibles with a slender and elongated horizontal ramus, a short ascending ramus,

255 a low coronoid process, a high condylar process, and a well individualized angular process (Fig.

$2565 \mathrm{~A})$. In terms of shape variation, PC2 (4.745\% of total shape variation) separates mandibles that

257 show an elongated anterior part of the horizontal ramus, a short tooth row, and a high and

258 distally oriented coronoid processes, from mandibles having a reduced anterior part of the

259 horizontal ramus, an elongated tooth row, and a low coronoid process. We observed even less

260 differentiation with shape data corrected for allometry (Figure S3), which indicates that some

261 specimens differ significantly in size. This is confirmed by a regression of the first principal

262 component on the logarithm of the centroid size (Fig. 5B), which shows that the specimens from

263 Brazil, Uruguay, Paraguay, Bolivia, Peru, Ecuador, Costa Rica, and Colombia are usually

264 smaller.

265 A MANOVA was also used to explore if the cranial variation matches the geographical

266 distributions of $D$. novemcinctus (Wilks' lambda $=2.97 \times 10^{-6}, \mathrm{~F}=2.157, \mathrm{p}<0.001$ ). When looking 
267 at the cranial morphological variation according to geographic origin (i.e., countries) (Fig. 6),

268 several trends can be observed. PC1, accounting for $22.7 \%$ of the overall variation, demonstrates

269 a change in how domed the dorsal surface of the skull is, and positively correlates with an

270 increase in snout length, a decrease in braincase size, jugals that are more extended

271 dorsoventrally, and shorter pterygoid processes (Fig. 6A). Specific clusters are recognizable on

272 the first principal component, with specimens from Brazil, Paraguay, Venezuela (NMNH 406700

273 from Clarines area, North), Ecuador (BMNH-14-4-25-86 from Gualaquiza, South East),

274 Colombia (AMNH 136252 from Villavicencio area, Centre), Peru, Bolivia, Paraguay, and

275 Uruguay that congregate in the negative values, whereas all other specimens lay in the positive

276 values. $\mathrm{PC} 2$ is responsible for $8.6 \%$ of the variance, and describes variation in the size of the

277 posterior part of the rostrum; it also displays variation in length of the posterior part of the palate

278 with an anterior border of the palatine that is well behind the posterior end of the tooth row in

279 skulls showing positive values. This axis mainly separates specimens from USA, Mexico, Belize,

280 Honduras, Guatemala, and Nicaragua (negative values) from other specimens (positive values).

281 We observed less specific differentiation with shape data corrected for allometry (Figure S4),

282 which shows that the different geographical subgroups differ significantly in size. This is

283 confirmed by a regression of the first principal component to the logarithm of the centroid size

284 (Fig. 7).

A Linear Discriminant Analysis (LDA) of shape coordinates was performed in order to 286 take into account the entirety of morphological variation (i.e., 35 first PCs that represent $90.6 \%$

287 of the variance) and to maximize discrimination among specimens belonging to different

288 countries. Only countries for which we had several specimens could be considered here. Three

289 main regional groups were clearly recovered by the analysis (Fig. 8A): a Northern morphotype, a 
290 Southern morphotype, and a group restricted to the Guiana Shield (GS). The first group from

291 North and Central America includes specimens from the US, Mexico, Guatemala, and Belize.

292 The South American group gathers specimens from Brazil, Uruguay, Bolivia, Peru, Colombia,

293 and Venezuela. Finally, specimens from French Guiana, Suriname, and Guyana congregate in a

294 last distinctive group. Some specimens from Colombia, Venezuela, and Ecuador do not gather

295 with any of those groups and sit in the middle of the graph defined by the first two discriminant

296 axes; these specimens are, however, well discriminated on the third and fourth discriminant axes

297 (Fig. 8B) and might constitute a fourth individualized regional group among D. novemcinctus,

298 called hereafter the Central morphotype.

299 The discriminant model used to separate the regional groups, based on artificial

300 boundaries (i.e. borders of countries), was checked using a classification phase. The same

301 procedure was then used on under-sampled countries (i.e., when $\mathrm{n}=1$ ) to assess their affiliation to

302 one of the four abovementioned groups. This analysis showed $95 \%$ correct classification of

303 specimens (Table S2). Most regional misclassifications were with specimens coming from the

304 limit of the distribution range of the groups. Two Brazilian specimens from Amapa are put

305 together with the Guianan specimens (Table S2) and confirm previous results from the PCA,

306 where these two specimens clearly depart from the rest of the Brazilian specimens (Fig. 6A).

307 Three specimens from Venezuela (NMNH 406700 from Clarines area, North), Ecuador (BMNH-

308 14-4-25-86 from Gualaquiza, South East), and Colombia (AMNH 136252 from Villavicencio

309 area, Centre) were a posteriori classified as close to the Southern morphotype. All these

310 specimens were collected East of the Andes (Fig. 9) and grouped with Brazilian specimens in the

311 PCA analyses. Concerning the countries for which only one specimen was available, the

312 classification analyses gave congruent results with the grouping proposed by the principal 
313 component analysis: specimens from Paraguay and Peru were classified as being part of the

314 Southern morphotype, whereas specimens from Nicaragua, Honduras, and Costa Rica were

315 classified as grouping with the Northern morphotype (Table S2). Using a reduced set of

316 landmarks, the specimen from Panama was attributed to the Central morphotype. When

317 performing these classification methods using the four groups as factors (i.e., Northern, Central,

318 Southern, and Guianan morphotypes; see Table S3), instead of countries, we retrieved $100 \%$

319 correct classification of specimens.

320 We performed similar analyses (PCA and LDA, see Figure S5) using linear cranial

321 measurements traditionally used in systematic studies. In all cases, these analyses failed to

322 retrieve a clear-cut discrimination between the four groups defined above.

323

324 Discussion

325 Morphological variation of skull among Dasypus species

326 Skull ratios are commonly used to compare Dasypus species, especially the length of the palate

327 to the length of the skull (PL/CNL), and the length of the rostrum to the length of the skull (RL

328 adj./CNL) (Wetzel, 1985). Three subgenera are commonly recognized on this basis:

329 Cryptophractus (including D. pilosus), Hyperoambon (including D. kappleri), and Dasypus

330 (including all remaining species) (Wetzel \& Mondolfi, 1979). Our results are largely consistent

331 with findings from previous studies regarding existing differences among Dasypus species.

332 Allometry substantially explains cranial differences, with the exception of D. pilosus, which does

333 not follow the main dasypodine allometric trend (Figs. 3 and 4). The hairy long-nosed armadillo

334 is clearly distinguished from the other four Dasypus species studied by a lengthening of the snout

335 and mandible and a lesser development of the braincase and basicranium. All these 
336 characteristics might be linked to their unique diet, which predominantly includes ants and

337 termites (Castro et al., 2015). Considering these distinctive morphological features and the

338 specific structure of its osteoderms, Castro et al. (2015) recently proposed including D. pilosus in

339 a different genus, Cryptophractus. However, recent molecular results (Gibb et al., 2016) did not

340 support such a taxonomic reassessment and argued for the retention of the hairy long-nosed

341 armadillo in the genus Dasypus. D. pilosus thus likely represents a case of rapid acquisition (i.e.,

$3422.8 \mathrm{Ma}$ as estimated by Gibb et al., 2016) of distinctive morphological traits in line with the shift

343 to a divergent behaviour, ecology, and high altitude habitat.

344 Both molecular and morphological data suggested that $D$. kappleri is broadly separated

345 from the other Dasypus species (Wetzel \& Mondolfi, 1979; Gibb et al., 2016), but contrary to

346 results of Castro et al. (2015) in which it is the crown group. Mitogenomic data clearly identified

347 D. kappleri as the sister group to all other Dasypus species, from which it diverged more than 12

348 million years ago (Gibb et al., 2016), and Gibb et al. (2016) suggested placing it in the distinct

349 genus Hyperoambon, as originally proposed by Wetzel and Mondolfi (1979). D. kappleri

350 exhibited significant morphological differentiation in our results, with all the specimens

351 congregating in the morphospace at least in part because they are much larger than the other

352 species. However, the cranial morphology of $D$. kappleri still remains very close to that of $D$.

353 novemcinctus when compared to that of D. septemcinctus, D. hybridus, and D. pilosus (Fig. 4).

354 D. kappleri also grouped with D. novemcinctus to the exclusion of these latter taxa in Castro et

355 al. (2015). Recently, Feijo and Cordeiro-Estrela (2016) proposed recognizing three species

356 within $D$. kappleri based on morphological differences of the skull and carapace: $D$. kappleri

357 distributed in the Guiana shield; D. pastasae occurring from the eastern Andes of Peru, Ecuador,

358 Colombia, and Venezuela south of the Orinoco River into the western Brazilian Amazon; and 
359 finally D. beniensis that occurs in the lowlands of the Amazonian Brazil and Bolivia to the south

360 of the Madre de Dios, Madeira, and the lower Amazon rivers. We only had access to a limited

361 number of specimens, but did not retrieve such a clear geographical segregation in shape (Figure

362 S6A), while we observed a mild differentiation in size with the Guianan D. kappleri usually

363 being bigger (Figure S6B).

364 Wetzel and Mondolfi (1979:47) placed D. septemcinctus, D. hybridus, and D. sabanicola

365 in the same subgenus together with $D$. novemcinctus. We observed that D. hybridus and D.

366 septemcinctus group together in the morphospace, but are largely separated from $D$.

367 novemcinctus. These two species are usually distinguished by external features, $D$. hybridus

368 possessing shorter ears and a longer tail than D. septemcinctus (Hamlett, 1939; Wetzel \&

369 Mondolfi, 1979). Our morphometrical results showed that D. hybridus and D. septemcinctus

370 display very similar cranial and mandibular morphologies. They also display several cranial

371 characteristics in common with juvenile specimens of $D$. novemcinctus. Such morphological

372 similarities echo recent molecular findings (Gibb et al., 2016) which showed that mitogenomic

373 sequences of $D$. hybridus were almost identical to those of an Argentinian D. septemcinctus

374 (99.3\% identity). The two species were considered as valid based on cranial and body

375 measurements (Hamlett, 1939; Wetzel, 1985) despite the fact that they display many external

376 resemblances and have overlapping geographical distributions. A recent study of their internal

377 cranial sinuses also failed to provide diagnostic characters for distinguishing these two species

378 (Billet et al., unpublished data). Our samples were very limited for both D. hybridus $(\mathrm{n}=4)$ and

379 D. septemcinctus ( $\mathrm{n}=3$ ), but additional sampling will undoubtedly help to define the systematic

380 status of the two species. 
We did not have access to the two most recently recognized Dasypus species: the

382 Yunga's lesser long-nosed armadillo D. mazzai (Yepes, 1933; Vizcaíno, 1995; Feijo \& Cordeiro-

383 Estrela, 2014), and the northern long-nosed armadillo D. sabanicola (Mondolfi, 1967). The

384 validity of the former was and is still hotly debated (Wetzel \& Mondolfi, 1979; Vizcaíno, 1995;

385 Gardner, 2008; Feijo \& Cordeiro-Estrela, 2014), while the specific status of the latter also

386 remains controversial (Wetzel \& Mondolfi, 1979; Wetzel, 1985). Cranial morphometric data

387 might provide useful insights into the systematic status of the two species.

388

389

Morphological systematics and skull shape variation in Dasypus novemcinctus

390 Relative skull shape has previously been examined for systematic purposes in the genus

391 Dasypus, but never with a focus on patterns of intraspecific variation. Hamlett (1939) cast doubt

392 on the possibility of reliably identifying different subgroups within D. novemcinctus, although

393 early workers had already recognized several, either at a specific or at a subspecific level. Peters

394 (1864) described Dasypus fenestratus from Costa Rica based on the position of the small and

395 numerous major palatine foramina, some of which are connected to the incisive foramina

396 through a groove between (not in front of) the anterior teeth, as well as its medially shorter

397 maxillo-palatine bones, the position of the palatine suture posterior to the end of the tooth row,

398 the position of the lacrimal foramen closer to the orbital rim, and one character related to the

399 extent of the pelvic shield of the carapace. Gray (1873) tentatively recognized as many as seven

400 species of nine-banded armadillos in South and Central Americas, among which five were new:

401 Tatusia (=Dasypus) granadiana, T. leptorhynchus, T. brevirostris, T. leptocephala, and T.

402 boliviensis. He also followed Peters (1864) and recognized T. mexicana (a variety of D.

403 novemcinctus in Peters 1864), but decided to ignore T. fenestratus. Both Peters (1864) and Gray 
404 (1873) used a very small number of specimens, and Gray (1873) distinguished all these species

405 based mainly on the morphology of the lacrimal bones and minute morphological variations of

406 the head scutes. Allen (1911) later considered D. fenestratus and D. mexicanus as synonyms at

407 the subspecific level (D. novemcinctus fenestratus Peters). He also described D. novemcinctus

408 hoplites from Grenada, a subspecies that he considered to be distinctly characterized by a shorter

409 tooth row, due to the absence of the last tooth locus.

410 From the inspection of a series of specimens from Panama, Costa Rica, and Yucatan,

411 Allen (1911) also distinguished a Central American morphotype. Compared to Brazilian

412 specimens, Allen's Central American armadillo was characterized by short palatine bones that

413 did not reach the level of the most posterior teeth, an obvious inflation of the maxillary region

414 located in front of the lacrimal bone, and a lateral margin of the skull that was largely convex at

415 the level of the second or third tooth in ventral view. Based on size differences, Hagmann (1908)

416 described the subspecies D. n. mexianae, which he thought was restricted to a small area close to

417 the mouth of the Amazon River. Lönnberg (1913) defined D. n. aequatorialis from Ecuador,

418 which McBee and Baker (1982) later proposed considering a probable synonym to $T$.

419 granadiana Gray 1873. Lönnberg's comparisons were based on morphological characteristics of

420 the carapace, D. n. aequatorialis showing differences in the occipital portion of the frontal

421 shield, as well as different proportions of the scales of the shoulder and pelvic shields. Later on,

422 Russell (1953) proposed recognizing two subspecies in Mexico: D. $n$. davisi in the northwestern

423 part of Mexico, and D. n. mexicanus in the remaining part of the country. Even if it is close

424 morphologically to D. n. mexicanus, D. n. davisi is much smaller in size, and displays a few

425 distinctive features, such as small maxillary teeth, a narrow mandible with a posteriorly projected

426 angular process, and differences in suture closure patterns and shape, for instance with a parietal- 
427 frontal sutures that lies well behind the posterior process of the zygomatic arch (Russell, 1953).

428 Most of these early descriptions, be they at a specific or subspecific level, were based on subtle

429 morphological differences. No proper quantification of the skull variation was undertaken up

430 until now.

431 Our statistical analysis of skull shape demonstrated that D. novemcinctus exhibits a

432 significant level of intraspecific variation, with several clearly identified subgroups. Our

433 multivariate analyses suggest the absence of sexual dimorphism in the shape of the cranium and

434 a slight sexual dimorphism in the mandibular morphology. McBee \& Baker (1982) proposed that

435 male nine-banded armadillos tend to be slightly larger than females. However, Loughry \&

436 McDonough (2013) pointed out that McBee and Baker based this assertion on a paper that only

437 examined a very small number of animals, and reach the more general conclusion that there is no

438 sexual dimorphism in this species using measurements of hundreds of animals. Our univariate

439 analyses confirmed the absence of size differences between females and males D. novemcinctus.

440 We show that allometry is likely to explain a substantial part of the observed morphological

441 variation, including the geographical variation. Our morphometric analysis revealed distinct

442 geographical differentiation among nine-banded armadillos, both in size and shape. This echoes

443 early findings by Wetzel and Mondolfi (1979) who already pointed out size gradients among

444 different populations of D. novemcinctus. Interestingly, our geometric morphometric analyses

445 permitted us to define four discrete phenotypic units. These units display very different cranial

446 characters and occupy very distinct geographical distributions, which are in essence allopatric.

447 Specimens from Brazil, Uruguay, Paraguay, Bolivia, Peru, and from regions of Ecuador,

448 Colombia, and Venezuela located east of the Andes make up most of one group and show a very

449 stable pattern of variation (Fig. 9). They are on average smaller than the three remaining groups. 
450 Loughry \& McDonough (1998) already showed that body size of armadillos from Poco das

451 Antas (Brazil) was smaller than that of animals from the United States. Skulls of this Southern

452 morphotype are characterized by smaller and flatter skulls with short frontal sinuses, a narrow

453 snout with short premaxillary bones, a narrow interorbital width, a long and slender jugal part of

454 the zygomatic arch, long pterygoid processes, and a basicranium aligned with the palate in lateral

455 view (Fig. 6). We found no sign of morphological differentiation of specimens from the mouth

456 of the Amazon River, despite of the recognition of the subspecies D. n. mexianae (Hagmann,

457 1908). The area covered by the specimens attributed to this morphological unit fully

458 encompasses the Amazon basin and seemed to be delimitated by the Andes on the western side.

459 As a matter of fact, the single Ecuadorian specimen coming from the eastern side of the Andes

460 appeared to be distinct from most other Ecuadorian specimens, but morphologically close to

461 Brazilian and Bolivian specimens. The same holds true for the Peruvian, Colombian, and

462 Venezuelan specimens collected east of the Andes. The distribution of this group is reminiscent

463 of that of the subspecies D. novemcinctus novemcinctus Linnaeus, except for the Guiana Shield

464 area (Gardner, 2008). It also recalls a similar lineage molecularly identified (Arteaga et al.,

465 unpublished data) and the Southern morphotype evidenced by the analysis of paranasal spaces

466 (Billet et al., unpublished data). Unfortunately the type specimen of $D$. novemcinctus, which is

467 supposedly housed in the Swedish Museum of Natural History in Stockholm (Lönnberg, 1913),

468 could not be included in our analyses. The type locality of Dasypus novemcinctus Linnaeus is

469 "America meridionali" and is generally thought to be from the eastern coast of Brazil (Allen,

470 1911).

471 The next differentiated group is represented by individuals originating from the Guiana

472 shield region, including French Guiana, Guyana, Suriname, and Amapa in Brazil (Fig. 9). All the 
473 specimens belonging to this Guianan morphotype display large dome-shaped skulls that share

474 distinctive morphological features, including long frontal sinuses, a wide snout with long

475 premaxillary bones, a large interorbital width, large lacrimal bones, a short and massive jugal

476 part of the zygomatic arch, an anterior border of the palatine located well behind the posterior

477 end of the tooth row, short pterygoid processes, and a basicranium situated above the palatal

478 plane (Fig. 6). Studies of paranasal sinuses affirm the distinctness of this group and show that the

479 dome-shaped frontal region of Guianan nine-banded armadillos is occupied by a

480 characteristically inflated pair of frontal sinuses that extend posteriorly to the fronto-parietal

481 suture (Billet al., unpublished data). No subspecies has ever been recognized or proposed in this

482 part of South America, and such a clear-cut morphological divergence of Guianan specimens of

483 D. novemcinctus is here proposed for the first time. These morphometric findings corroborate

484 recent molecular studies, which showed that specimens from French Guiana are very distant

485 from the US populations (Huchon et al., 1999) and represent a distinct branch in the dasypodine

486 mitogenomic tree (Gibb et al., 2016).

487 The distribution of the third recognized morphological group is more limited. It is

488 distributed from the western Andes of Ecuador and Colombia to Venezuela, and Panama (Fig.

489 9). This Central morphotype is characterized by high and short skulls having moderately

490 developed frontal sinuses, long premaxillary bones, a narrow interorbital width (wider than

491 Southern specimens but narrower than Guianan specimens), a massive anterior part of the

492 zygomatic arch that is much larger than the posterior part, a short and high jugal part of the

493 zygomatic arch that is largely convex ventrally, an anterior border of the palatine located well

494 behind the posterior end of the tooth row, short pterygoid processes, and a basicranium well

495 above the palatal plane (Fig. 6). This distribution roughly corresponds to the combined ranges of 
496 two previously described subspecies, D. n. fenestratus (Peters, 1864) and D. n. aequatorialis

497 (Lönnberg, 1913) suggesting that these subspecies might be synonymous. However, we could

498 not fully test this hypothesis since we had access to only one specimen from west of the Andes in

499 Peru, Ecuador and southern Bolivia. Studies on the paranasal spaces (Billet et al., unpublished

500 data) failed to recognize such a group, and instead grouped some specimens from these regions

501 with specimens from North and Central America, whereas others (from the western parts of

502 Colombia, Venezuela and from Panama) could not confidently be referred to a given frontal

503 sinus morphotype. In contrast, molecular studies recovered a lineage similar to the group

504 recognized here, distributed from the Northern Andes to Central America and then expanding

505 into western Mexico (Arteaga et al., 2012).

506 The last distinct morphotype occurs from Nicaragua to the southeastern part of the US

507 (Fig. 9). The range of this Northern morphotype spans the proposed distribution areas of the

508 subspecies D. n. mexicanus and D. ndavisi, as well as the northernmost part of the distribution

509 range of $D . n$. fenestratus. All the skulls from this area display moderately developed frontal

510 sinuses convergent toward the midline, long premaxillary bones, a narrow interorbital width

511 (wider than Southern specimens but narrower than Guianan specimens), a long and slender jugal

512 part of the zygomatic arch that is largely convex ventrally, an anterior border of the palatine

513 located at the level of the posterior end of the tooth row, short pterygoid processes, and a

514 basicranium slightly above the palatal plane (Fig. 6). Contrary to Russell (1953), we did not find

515 major morphological cranial differences between north-western and eastern Mexican

516 populations. Our results thus cast doubts on the validity of the subspecies D. $n$. davisi. The

517 morphological homogeneity in this group is also at odds with the presence of two mitochondrial

518 lineages in Mexico (Arteaga et al., 2012), but is consistent with the presence of nuclear gene 
519 flow between them (Arteaga et al., 2011). This Northern group includes the invasive US

520 armadillo population, which is derived from two geographical sources: one from Mexico, and

521 one from south-central Florida, where captive animals were presumably released (Loughry \&

522 McDonough, 2013). Echoing the results obtained on six microsatellite loci described by Loughry

523 et al. (2009), our findings indicate a close relationship between the two US populations. The

524 recognition of this Northern unit with individuals ranging from Central to the southeastern US is

525 also in agreement with their distinctive pattern of paranasal sinuses (Billet et al., unpublished 526 data).

527 The newly recognized subgroups within D. novemcinctus prompt questions about the role 528 of ecological factors likely to have influenced their morphological differentiation. Variation in 529 skull morphology as a result of ecological factors has been studied in a number of species over 530 recent years (e.g., Caumul and Polly, 2005; Wroe and Milne, 2007; Hautier et al., 2012). Factors 531 such as temperature, diet and competition may cause phenotypic variation and are likely to 532 explain some morphological differences among the identified groups. These ecological factors

533 vary in relation to geography, and differences in geographical distribution can drive selection for 534 different phenotypes, which may eventually lead to distinctive populations or even new species.

535 Since the four D. novemcinctus subgroups are not sympatric in most of their respective natural 536 ranges, we can hypothesize that environment and/or genetic drift, but not competition, may be 537 responsible for some of the observed intraspecific variation. The northern Andes constitute a 538 clear geographical barrier, which limited contacts between northern/central and southern 539 populations, and thus has likely played a major role in shaping the morphological differentiation 540 of the long-nosed armadillos. This biogeographical barrier seems to have played a significant 541 role in xenarthran evolution and diversification in general (Moraes-Barros \& Arteaga, 2015), 
542 since it also marks the separation between the two living species of tamanduas, with Tamandua

543 mexicana in the north and T. tetradactyla in the south (Superina, Miranda \& Abba, 2010), as

544 well as between two living species of within naked-tailed armadillos, with Cabassous centralis

545 in the north and C. unicinctus in the south (Abba \& Superina, 2010).

546 The geographical distribution of the divergent populations of $D$. novemcinctus recalls the

547 pattern of morphological differentiation recently proposed for the greater long-nosed armadillo

548 (D. kappleri), especially for the Guianan specimens (Feijo \& Cordeiro-Estrela, 2016). However,

549 in the nine-banded armadillo, we did not find a clear morphological differentiation within the

550 Amazonian basin, as defined by the opposite banks of the Madeira-Madre de Dios rivers (Feijo

551 \& Cordeiro-Estrela, 2016), which separate D. pastasae from D. beniensis. Given the extent of

552 morphological variation reported within D. kappleri, Feijo and Cordeiro-Estrela (2016)

553 interpreted their findings as indicative of the fact that this species complex diverged earlier than

554 other Dasypus species, which would allow them to accumulate more differences. Such a

555 hypothesis seems difficult to support, in view of the substantial morphological variation

556 observed among different populations of $D$. novemcinctus, which have diverged more recently

557 (3.7 Ma, Gibb et al., 2016). Feijo and Cordeiro-Estrela (2016) also proposed that such

558 cumulative differences may result from strong environmental selective pressures. The newly

559 discovered morphological diversity within D. kappleri and D. novemcinctus is likely to represent

560 parallel cases of allopatric differentiation in response to diverging environmental pressures. In

561 both cases, only the future collecting of large-scale genomic nuclear data will allow testing of

562 these taxonomic proposals based on morphological data.

563

564 Conclusions 
If our interspecific comparisons primarily just provide additional support for the current

566 designation of each group as a separate taxon, the intraspecific analyses of variation within $D$.

567 novemcinctus enable detection of previously overlooked morphotypes. Our study of the

568 intraspecific variation of the skull in D. novemcinctus reveals clear links to geographic

569 distribution, and allows a revision of past taxonomic delimitations. Based on the cranial

570 differences observed, we consider that $D$. novemcinctus should be regarded either as a polytypic

571 species (with three to four subspecies) or as a complex of several species (with three to four

572 species). A new unit of nine-banded armadillos from the Guiana Shield could be established,

573 which is in agreement with most recent investigations of molecular data and internal anatomy

574 (Loughry \& McDonough, 2013; Billet G., unpublished data). At this stage, we refrain to make

575 definitive taxonomic pronouncements for the four morphological subsets in the absence of a

576 more exhaustive molecular sampling allowing a complete taxonomic reassessment of the genus

577 (Arteaga M-C., unpublished data). The discovery of divergent populations within $D$.

578 novemcinctus has implications for conservation of the species. In some areas, human activities

579 have led to habitat degradation and fragmentation (Zimbres et al., 2013) or even to habitat loss.

580 These divergent populations may be under threat and may require specific conservation

581 measures, or at least a close re-examination of their conservation status. If we were to consider

582 them as separate management units and not as a single species with a large distribution, the

583 threat of endangerment to $D$. novemcinctus may merit re-evaluation, since it is currently

584 classified globally as 'Least Concern' by the IUCN (Loughry, McDonough \& Abba, 2014). In

585 addition, our results demonstrate that specimens of $D$. novemcinctus should be chosen with

586 caution when making anatomical comparisons or performing cladistic analyses (e.g., Castro et

587 al., 2015); their geographical distribution should be at least specified in all cases. Lastly, 
588 morphological investigation of intra- and interspecific variation in Dasypus needs to be extended

589 to the other parts of the body, the carapace in particular. The cranial differences detected among

590 the defined groups might be linked to previously detected differences in the number and shape of

591 scutes on the head shield (e.g., Lönnberg, 1913), for example. Geometric morphometric data

592 holds out the possibility of effectively studying covariation patterns among osteological parts and

593 features of the carapace. Given the quality of the cingulate fossil record, using geometric

594 morphometric methods seems likely to be equally useful on extinct forms, and so might also

595 provide fruitful ways to interpret past morphological diversity.

596

597 Acknowledgements

598 We are grateful to Christiane Denys, Violaine Nicolas, and Géraldine Véron, (Muséum National

599 d'Histoire Naturelle, Paris, France), Roberto Portela Miguez, Louise Tomsett and Laura Balcells

600 (British Museum of Natural History, London, UK), Eileen Westwig (American Museum of

601 Natural History, New-York, USA), Burton Lim (Royal Ontario Museum, Toronto, Canada),

602 Nicole Edmison and Chris Helgen (National Museum of Natural History, Washington, DC,

603 USA), Jake Esselstyn (Louisiana State University, Museum of Natural Sciences, Bâton-Rouge,

604 USA), Manuel Ruedi (Muséum d'Histoire naturelle, Geneva, Switzerland), Claudia Regina da

605 Silva (Instituto de Pesquisas Científicas e Tecnológicas do Estado do Amapá, Macapá, Brazil),

606 Steven van der Mije (Naturalis Biodiversity Center, Leiden, Netherland), François Cazeflis and

607 Suzanne Jiquel (Institut des Sciences de l'Evolution, Montpellier, France), Lucile Dudoignon

608 (KWATA association, Cayenne, France), Dominique Charles (CNRS, Montpellier, France),

609 Maria-Clara Arteaga, Maria Nazareth da Silva (Instituto de Pesquisas Científicas e Tecnológicas

610 do Estado do Amapá, Macapá, Brazil) for access to comparative material. We thank Clara 
611 Belfiore for her help in the data acquisition and Rémi Lefebvre for interesting discussions on the

612 dataset. R. Lebrun (Institut des Sciences de l'Evolution, Montpellier, France), Farah Ahmed

613 (British Museum of Natural History, London, UK), Miguel García-Sanz and Florent Goussard

614 (Platform AST-RX MNHN, Paris, France) generously provided help and advice on the

615 acquisition of CT scans. Some of the experiments were performed using the $\mu$-CT facilities of

616 the Montpellier Rio Imaging (MRI) platform and of the LabEx CeMEB. In compliance with

617 Advantages and Benefits Sharing policy in French Guiana, material from French Guiana has

618 been registred in the collection JAGUARS (http://kwata.net/la-collection-jaguars-pour-1-etude-

619 de-la-biodiversite.html; CITES reference: FR973A) supported by Kwata NGO, Institut Pasteur

620 de la Guyane, DEAL Guyane, and Collectivité Territoriale de la Guyane. This is contribution

621 ISEM 2017-XXX of the Institut des Sciences de l'Evolution.

622

623 References

624 Abba AM., Superina M. 2010. The 2009/2010 armadillo Red List assessment. Edentata 11:135$625 \quad 184$.

626 Allen G. 1911. Mammals of the West Indies. Bulletin of the Museum of Comparative Zoology $627 \quad 54: 175-263$.

628 Arteaga MC., McCormack JE., Eguiarte LE., Medellín RA. 2011. Genetic admixture in 629 multidimensional environmental space: asymmetrical niche similarity promotes gene flow 630 in armadillos (Dasypus novemcinctus). Evolution 65:2470-2480.

631 Arteaga MC., Piñero D., Eguiarte LE., Gasca J., Medellín R. 2012. Genetic structure and 632 diversity of the nine-banded armadillo in Mexico. Journal of Mammalogy 93:547-559.

633 Asher RJ., Lehmann T. 2008. Dental eruption in afrotherian mammals. BMC biology 6:14. DOI: 
635 Bookstein F. 1991. Morphometric Tools for Landmark Data. Geometry and biology. Cambridge: 636 Cambridge University Press.

637 Carlini AA., Castro MC., Madden RH., Scillato-Yané GJ. 2013. A new species of Dasypodidae 638 (Xenarthra: Cingulata) from the late Miocene of northwestern South America: implications 639 in the Dasypodini phylogeny and diversity. Historical Biology:37-41. DOI: 10.1080/08912963.2013.840832.

641 Carlini AA., Vizcaíno SF., Scillato-yané GJ. 1997. Armored xenarthrans: a unique taxonomic 642 and ecologic assemblage. In: Kay R, Madden R, Cifelli R, Flynn J. eds. Vertebrate 643 644 Paleontology in the Neotropics. The Miocene Fauna of La Venta, Colombia.

645 Castro MC. 2015. Sistemática y evolución de los armadillos Dasypodini (Xenarthra, Cingulata, 646 Dasypodidae). Revista del Museo de La Plata 15:1-50.

647 Castro MC., Avilla LS., Freitas ML., Carlini AA. 2013a. The armadillo Propraopus sulcatus 648 (Mammalia: Xenarthra) from the late Quaternary of northern Brazil and a revised synonymy 649 with Propraopus grandis. Quaternary International 317:80-87. DOI: 10.1016/j.quaint.2013.04.032.

651 Castro MC., Carlini AA., Sánchez R., Sánchez-Villagra MR. 2014. A new Dasypodini armadillo 652 (Xenarthra: Cingulata) from San Gregorio Formation, Pliocene of Venezuela: affinities and 653 biogeographic interpretations. Naturwissenschaften 101:77-86. DOI: 10.1007/s00114-0131131-5.

655 Castro MC., Ciancio MR., Pacheco V., Salas-Gismondi RM., Bostelmann JE., Carlini AA. 2015. 656 Reassessment of the hairy long-nosed armadillo "Dasypus"pilosus (Xenarthra, 
657 Dasypodidae) and revalidation of the genus Cryptophractus Fitzinger, 1856. Zootaxa $658 \quad 3947: 30-48$. DOI: 10.11646/zootaxa.3947.1.2.

659 Castro MC., Ribeiro AM., Ferigolo J., Langer MC. 2013b. Redescription of Dasypus punctatus

660 Lund, 1840 and considerations on the genus Propraopus Ameghino, 1881. Journal of 661 Vertebrate Paleontology 33:434-447. DOI: 10.1080/02724634.2013.729961.

662 Caumul R., Polly P. 2005. Phylogenetic and environmental components of morphological 663 variation: skull, mandible, and molar shape in marmots (Marmota, Rodentia). Evolution $664 \quad 59: 2460-2472$.

665 Ciancio MR., Castro MC., Galliari FC., Carlini AA., Asher RJ. 2012. Evolutionary implications 666 of dental eruption in Dasypus (Xenarthra). Journal of Mammalian Evolution 19:1-8. DOI: $667 \quad 10.1007 / \mathrm{s} 10914-011-9177-7$.

668 Delsuc F., Superina M., Tilak M., Douzery EJP., Hassanin A. 2012. Molecular phylogenetics 669 unveils the ancient evolutionary origins of the enigmatic fairy armadillos. Molecular $670 \quad$ Phylogenetics and Evolution 62:673-680. DOI: 10.1016/j.ympev.2011.11.008.

671 Dryden I., Mardia K. 1998. Statistical Shape Analysis. Chichester: John Wiley \& Sons.

672 Feijo A., Cordeiro-Estrela P. 2014. The correct name of the endemic Dasypus (Cingulata:

673 Dasypodidae) from northwestern Argentina. Zootaxa 3887:88-94. DOI:

$674 \quad$ 10.11646/zootaxa.3887.1.6.

675 Feijo A., Cordeiro-Estrela P. 2016. Taxonomic revision of the Dasypus kappleri complex, with 676 revalidations of Dasypus pastasae (Thomas, 1901) and Dasypus beniensis Lönnberg, 1942 677 (Cingulata, Dasypodidae). Zootaxa 4170:271-297. DOI: 10.11646/zootaxa.4170.2.3.

678 Gardner AF. 2008. Mammals of South America, Volume 1, Marsupials, Xenarthrans, Shrews, 679 and Bats. Chicago and London: The University of Chicago Press. 
680 Gaudin TJ., Wible JR. 2006. The phylogeny of living and extinct armadillos (Mammalia,

681 Xenarthra, Cingulata): a craniodental analysis. In: Carrano M, Gaudin TJ, Blob R, Wible JR 682 eds. Amniote Paleobiology: Perspectives on the Evolution of Mammals, Birds and Reptiles. 683 Chicago: The University of Chicago Press, 153-198.

684 Gibb GC., Condamine FL., Kuch M., Enk J., Moraes-Barros N., Superina M., Poinar HN., 685 Delsuc F. 2016. Shotgun mitogenomics provides a reference phylogenetic framework and 686 timescale for living xenarthrans. Molecular Biology and Evolution 33:621-642. DOI: $687 \quad 10.1093 / \mathrm{molbev} / \mathrm{msv} 250$.

688 Gray J. 1873. Handlist of the Edentate, Thick-skinned, and Ruminant Mammals of the British 689 Museum. London: British Museum of Natural History.

690 Hagmann G. 1908. Die Landsäugetiere der insel Mexiana. Als Beispiel der Einwirkung der 691 isolation auf die umbildung der arten. Arch. Rass.-Gesell.-Biol. München 5:1-32.

692 Hamlett G. 1939. Identity of Dasypus septemcinctus Linnaeus with notes on some related $693 \quad$ species. Journal of Mammalogy 20:328-336.

694 Hammer Ø., Harper D., Ryan P. 2001. PAST: paleontological statistics software package for $695 \quad$ education and data analysis. Palaeontologica Electronica 4:9.

696 Hautier L., Billet G., Eastwood B., Lane J. 2014. Patterns of morphological variation of extant 697 sloth skulls and their implication for future conservation efforts. Anatomical Record 698 297:979-1008. DOI: 10.1002/ar.22916.

699 Hautier L., Lebrun R., Cox PG. 2012. Patterns of covariation in the masticatory apparatus of

700 hystricognathous rodents: implications for evolution and diversification. Journal of $701 \quad$ morphology 273:1319-37. DOI: 10.1002/jmor.20061.

702 Hensel R. 1872. Beiträge zur Kenntnis der Säugethiere Süd-Brasiliens. Berlin: lis den 
703 Abhandlungen der Königl. Akademie der Wissenschaften.

704 Huchon D., Delsuc F., Catzeflis F., Douzery EJP. 1999. Armadillos exhibit less genetic

705 polymorphism in North America than in South America: nuclear and mitochondrial data

706 confirm founder effect in Dasypus novemcinctus (Xenarthra). Molecular Ecology 8:1743-

$707 \quad 1748$.

708 Lebrun R. 2008. Evolution and development of the strepsirrhine primate skull. University

709 Montpellier II and University of Zürich.

710 Lebrun R. 2014. ISE-MeshTools, a 3D interactive fossil reconstruction freeware. In: 12th Annual

711 Meeting of EAVP. Torino,

712 Lebrun R., Ponce de León M., Tafforeau P., Zollikofer C. 2010. Deep evolutionary roots of

713 strepsirrhine primate labyrinthine morphology. Journal of Anatomy 216:368-380.

714 Linnaeus C. 1758. Systema Naturae, Ed; 10. L. Uppsala: Salvii.

715 Lönnberg E. 1913. Mammals from Ecuador and related forms. Arkiv för Zoologi 8:1-36.

716 Loughry WJ., McDonough CM. 1998. Comparisons between nine-banded armadillo (Dasypus

717 novemcinctus) populations in Brazil and the United States. Revista de biología tropical

$718 \quad 46: 1173-1183$.

719 Loughry WJ., McDonough CM. 2013. The Nine-banded Armadillo: a Natural History. Norman:

$720 \quad$ University of Oklahoma Press.

721 Loughry J., McDonough C., Abba A. 2014. Dasypus novemcinctus. The IUCN Red List of

$722 \quad$ Threatened Species 2014:e.T6290A47440785.

723 Loughry WJ., Truman RW., McDonough CM., Tilak M-K., Garnier S., Delsuc F. 2009. Is

724 leprosy spreading among nine-banded armadillos in the southeastern United States? Journal

725 of Wildlife Diseases 45:144-152. DOI: 10.7589/0090-3558-45.1.144. 
726 McBee K., Baker RJ. 1982. Dasypus novemcinctus. Mammalian Species 162:1-9.

727 Mondolfi E. 1967. Descripción de un nuevo armadillo del género Dasypus de Venezuela

728 (Mammalia-Edentata). Memorias de la Sociedad de Ciencias Naturales La Salle 78:149$729 \quad 167$.

730 Moraes-Barros N., Arteaga MC. 2015. Genetic diversity in Xenarthra and its relevance to 731 patterns of Neotropical biodiversity. Journal of Mammalogy 96:1-13. DOI:

$732 \quad 10.1093 /$ jmammal/gyv077.

733 Peters W. 1864. Über neue Arten de Saugethier-gattungen Geomys, Haplodon und Dasypus.

734 Monatsbericht der Königlich-Preussischen Akademie der Wissenschaften zu Berlin $735 \quad 1865: 177-181$.

736 Rohlf F. 1999. Shape statistics: Procrustes superimpositions and tangent spaces. Journal of 737 Classification 16:197-223.

738 Russell R. 1953. Description of a new armadillo (Dasypus novemcinctus) from mexico with 739 remarks on geographic variation of the species. Proceedings of the Biological Society of $740 \quad$ Washington 66:21-26.

741 Smith LL., Doughty RW. 1984. The Amazing Armadillo: Geography of a Folk Critter. Austin: $742 \quad$ University of Texas Press.

743 Specht M. 2007. Spherical surface parameterization and its application to geometric 744 morphometric analysis of the braincase. University of Zürich Irchel.

745 Specht M., Lebrun R., Zollikofer C. 2007. Visualizing shape transformation between

746 chimpanzee and human braincases. The Visual Computer 23:743-751.

747 Superina M., Miranda FR., Abba AM. 2010. The 2010 anteater Red List assessment. Edentata $748 \quad 11: 96-114$. 
749 Taulman JF., Robbins LW. 2014. Range expansion and distributional limits of the nine-banded

750 armadillo in the United States: an update of Taulman \& Robbins (1996). Journal of

751 Biogeography 41:1626-1630.

752 Vizcaíno SF. 1995. Identificación especifica de las “mulitas”, género Dasypus L. (Mammalia;

753 Dasypodidae); del noroeste argentino. Descripción de una nueva especie. Mastozoologia

$754 \quad$ Neotropical 2:5-13.

755 Wetzel R. 1985. Taxonomy and distribution of armadillos. In: Montgomery GG ed. The

756 Evolution and Ecology of Armadillos, Sloths, and Vermilinguas. Washington DC:

757 Smithsonian Institution Press, 23-46.

758 Wetzel R., Mondolfi E. 1979. The subgenera and species of long-nosed armadillos, genus

759 Dasypus. In: Eisenberg J ed. Vertebrate Ecology in the Northern Neotropic. Washington

760 DC: Smithsonian Institution Press, 43-63.

761 Wilson D., Reeder D. 2005. Mammal Species of the World: a Taxonomic and Geographic

762 Reference. 3rd ed. Baltimore: Johns Hopkins University Press.

763 Wroe S., Milne N. 2007. Convergence and remarkably consistent constraint in the evolution of

764 carnivore skull shape. Evolution 61:1251-1260.

765 Yepes J. 1933. Una especie nueva de "mulita" (Dasypodinae) para el norte argentino. Physis

$766 \quad 11: 225-232$.

767 Zimbres B., Furtado MM., Jácomo, Anah T. A. Silveira L., Sollmann R., Tôrres NM., Machado

768 RB., Marinho-Filho J. 2013. The impact of habitat fragmentation on the ecology of

769 xenarthrans (Mammalia) in the Brazilian Cerrado. Lanscape Ecology 28:259-269.

770

771 Table legends 
772 Table 1. Definitions of the landmarks used on the mandible.

773

774 Table 2. Definitions of the landmarks used on the cranium. Landmarks indicated with a star 775 were not used in the intraspecific comparisons. 


\section{Figure Legends}

777

778 Figure 1. Landmarks digitized on the mandible and the skull. Dorsal (A), lateral (B), and ventral

779 views of the cranium; medial (C) and lateral (D) views of the mandible.

780

781 Figure 2. Illustration of the skull linear measurements. In blue, traditional measurements used in

782 Wetzel (1985). Abbreviations: LTC, length between the anterior tip of the nasal and the

783 posteriormost point of the supraoccipital; LR, rostral length; IOB, interorbital breadth; ILFB,

784 inter lacrimal foramina breadth; BB, distance between the left and right intersections between the

785 frontal, parietal, and squamosal sutures; NB, nasal breadth at the level of the nasal/frontal suture;

786 NL, nasal length; LCB, length between the anterior tip of the premaxillar and the condyles; TL,

787 length of the tooth row; $\mathrm{PB}$, palate breadth posterior to the last premolar; BZP, distance between

788 the infraorbital and the maxillary foramina; MB, inter-meatus breadth; OCB, breadth between

789 the lateral border of the occipital condyle.

790

791 Figure 3. (A) Principal component analysis (PC1 vs PC2) and associated patterns of

792 morphological transformation for the mandible of five Dasypus species. (B) Regression of the

793 first principal component on the logarithm of the centroid size $\left(\mathrm{R}^{2}=0.23 ; \mathrm{p}<0.001\right)$. Symbols:

794 blue squares, D. kappleri; black crosses, D. novemcinctus; green triangles, D. hybridus; green

795 diamonds, D. septemcinctus; red circles, D. pilosus.

796

797 Figure 4. (A) Principal component analysis (PC1 vs PC2) and associated patterns of

798 morphological transformation for crania of five Dasypus species. (B) Regression of the first 
799 principal component on the logarithm of the centroid size $\left(\mathrm{R}^{2}=0.50 ; \mathrm{p}<0.001\right)$. Symbols: blue

800 squares, D. kappleri; black crosses, D. novemcinctus; green triangles, D. hybridus; green

801 diamonds, D. septemcinctus; red circles, D. pilosus.

802

803 Figure 5. (A) Principal component analysis (PC1 vs PC2) and associated patterns of

804 morphological transformation for mandibles of Dasypus novemcinctus. (B) Regression of the

805 first principal component on the logarithm of the centroid size $\left(\mathrm{R}^{2}=0,035 ; \mathrm{p}=0.03\right)$. Symbols:

806 green diamonds, Bolivia; green triangle, Brazil (solid green triangles are for specimens from

807 Amapa); green circles, Paraguay; green crosses, Peru; green squares, Uruguay; green bars,

808 Venezuela; blue diamonds, Belize; blue "plus", Guatemala; blue bars, Honduras; blue squares,

809 Mexico; blue crosses, Nicaragua; blue triangles, USA; blue circles, Costa Rica; black triangles,

810 Colombia; black crosses, Ecuador; black stars, Panama; orange squares, French Guiana; orange

811 crosses, Guyana; orange circles, Suriname.

812

813 Figure 6. Principal component analysis (A, PC1 vs PC2; B, PC3 vs PC4) and associated patterns

814 of morphological transformation for crania of Dasypus novemcinctus. Symbols: green diamonds,

815 Bolivia; green triangle, Brazil (solid green triangles are for specimens from Amapa); green

816 circles, Paraguay; green crosses, Peru; green squares, Uruguay; green bars, Venezuela; blue

817 diamonds, Belize; blue "plus”, Guatemala; blue bars, Honduras; blue squares, Mexico; blue

818 crosses, Nicaragua; blue triangles, USA; blue circles, Costa Rica; black triangles, Colombia;

819 black crosses, Ecuador; orange squares, French Guiana; orange crosses, Guyana; orange circles,

820 Suriname.

821 
822 Figure 7. Regression of the first cranial principal component (Dasypus novemcinctus) on the

823 logarithm of the centroid size $\left(\mathrm{R}^{2}=0.15 ; \mathrm{p}<0.001\right)$. Symbols: green diamonds, Bolivia; green

824 triangle, Brazil (solid green triangles are for specimens from Amapa); green circles, Paraguay;

825 green crosses, Peru; green squares, Uruguay; green bars, Venezuela; blue diamonds, Belize; blue

826 "plus", Guatemala; blue bars, Honduras; blue squares, Mexico; blue crosses, Nicaragua; blue

827 triangles, USA; blue circles, Costa Rica; black triangles, Colombia; black crosses, Ecuador;

828 orange squares, French Guiana; orange crosses, Guyana; orange circles, Suriname.

829

830 Figure 8. Linear Discriminant Analysis (LDA) performed on cranial shape coordinates of

831 Dasypus novemcinctus. Symbols: green diamonds, Bolivia; green triangle, Brazil (solid green

832 triangles are for specimens from Amapa); green circles, Paraguay; green crosses, Peru; green

833 squares, Uruguay; green bars, Venezuela; blue diamonds, Belize; blue “plus”, Guatemala; blue

834 bars, Honduras; blue squares, Mexico; blue crosses, Nicaragua; blue triangles, USA; black

835 triangles, Colombia; black circles, Costa Rica; black crosses, Ecuador; orange squares, French

836 Guiana; orange crosses, Guyana; orange circles, Suriname.

837

838 Figure 9. Summary map showing the geographical distribution of nine-banded armadillo

839 specimens investigated in this study and their attribution to one of the four main morphotypes

840 defined in this study: black, Central group; blue, Northern group; green, Southern group; orange,

841 Guianan group. Specimens lacking precise geographical information (other than country of

842 origin) are indicated with a square. 


\section{Figure 1}

Figure 1

Landmarks digitized on the mandible and the skull. Dorsal (A), lateral (B), and ventral views of the cranium; medial (C) and lateral (D) views of the mandible. 


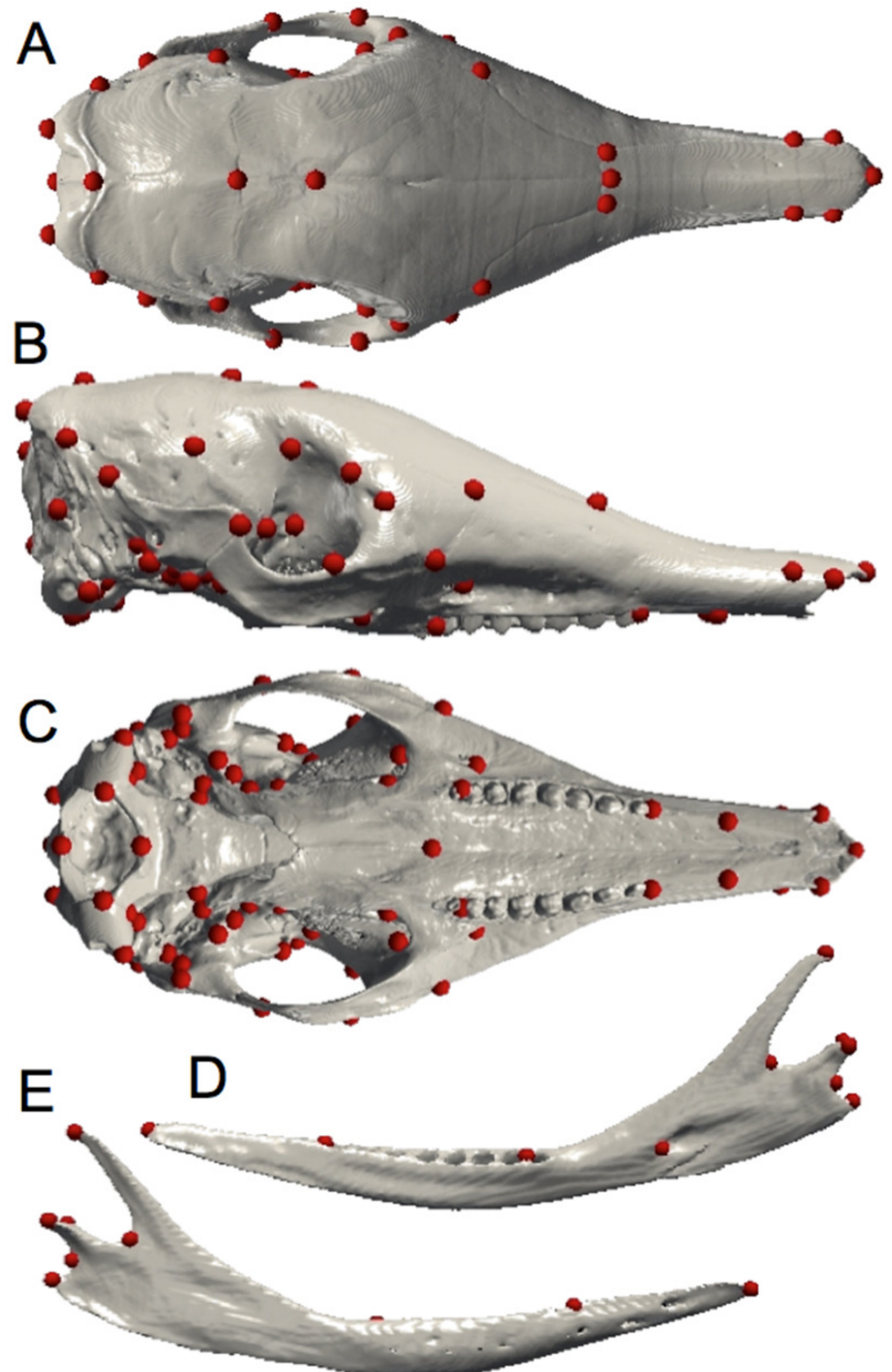




\section{Figure 2}

Figure 2

Illustration of the skull linear measurements. In blue, traditional measurements used in Wetzel (1985) . Abbreviations: LTC, length between the anterior tip of the nasal and the posteriormost point of the supraoccipital; LR, rostral length; IOB, interorbital breadth; ILFB, inter lacrimal foramina breadth; BB, distance between the left and right intersections between the frontal, parietal, and squamosal sutures; NB, nasal breadth; NL, nasal length; $L C B$, length between the anterior tip of the premaxillar and the condyles; $T L$, length of the tooth row; PB, palate breadth; BZP, distance between the infraorbital and the maxillary foramina; $\mathrm{MB}$, inter-meatus breadth; OCB, breadth between the lateral border of the occipital condyle. 

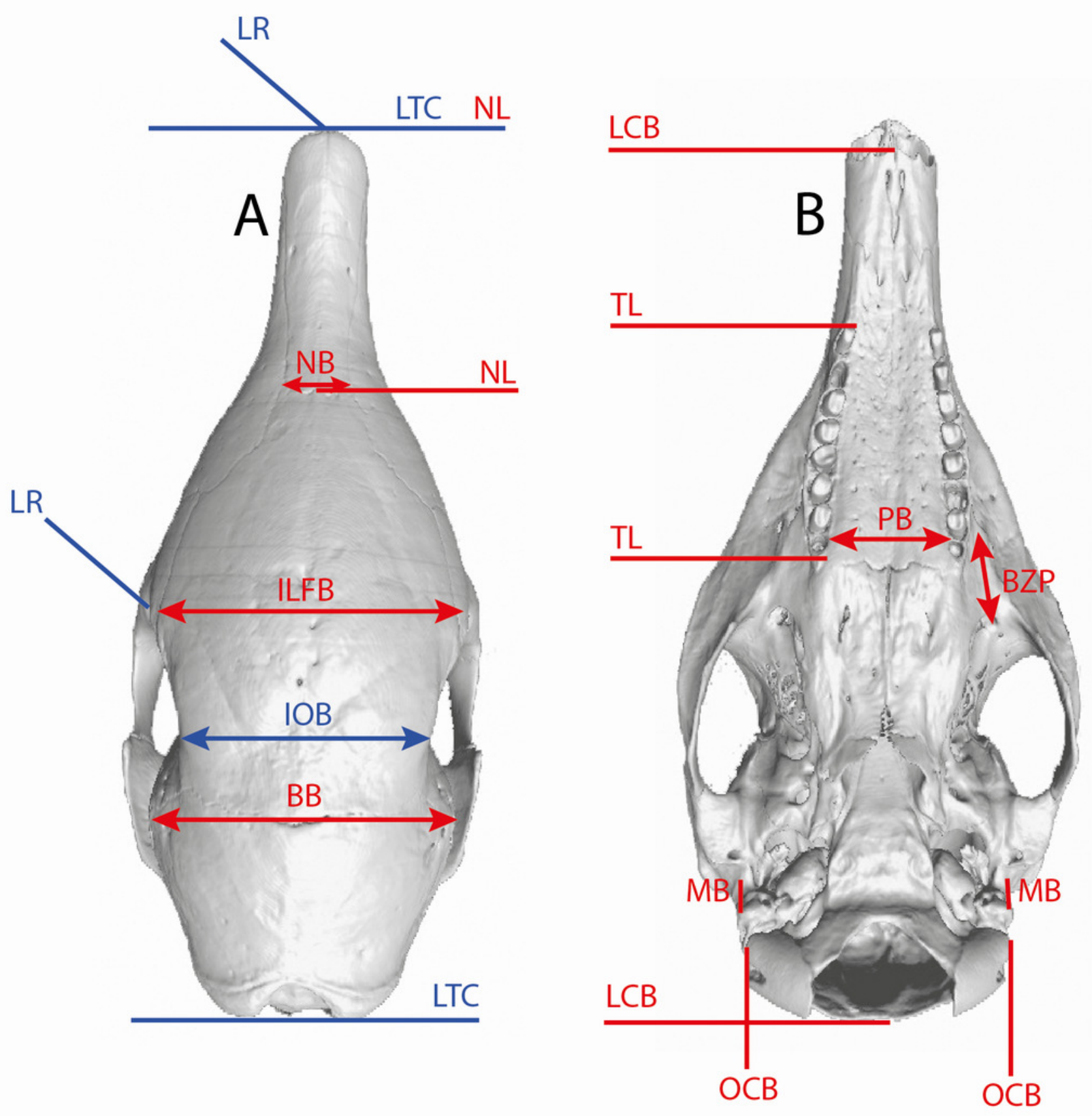
Figure 3

Figure 3

(A) Principal component analysis (PC1 vs PC2) and associated patterns of morphological transformation for the mandible of five Dasypus species. (B) Regression of the first principal component on the logarithm of the centroid size $\left(R^{2}=0.23 ; p<0.001\right)$. Symbols: blue squares, $D$. kappleri; black crosses, D. novemcinctus; green triangles, $D$. hybridus; green diamonds, $D$. septemcinctus; red circles, D. pilosus.
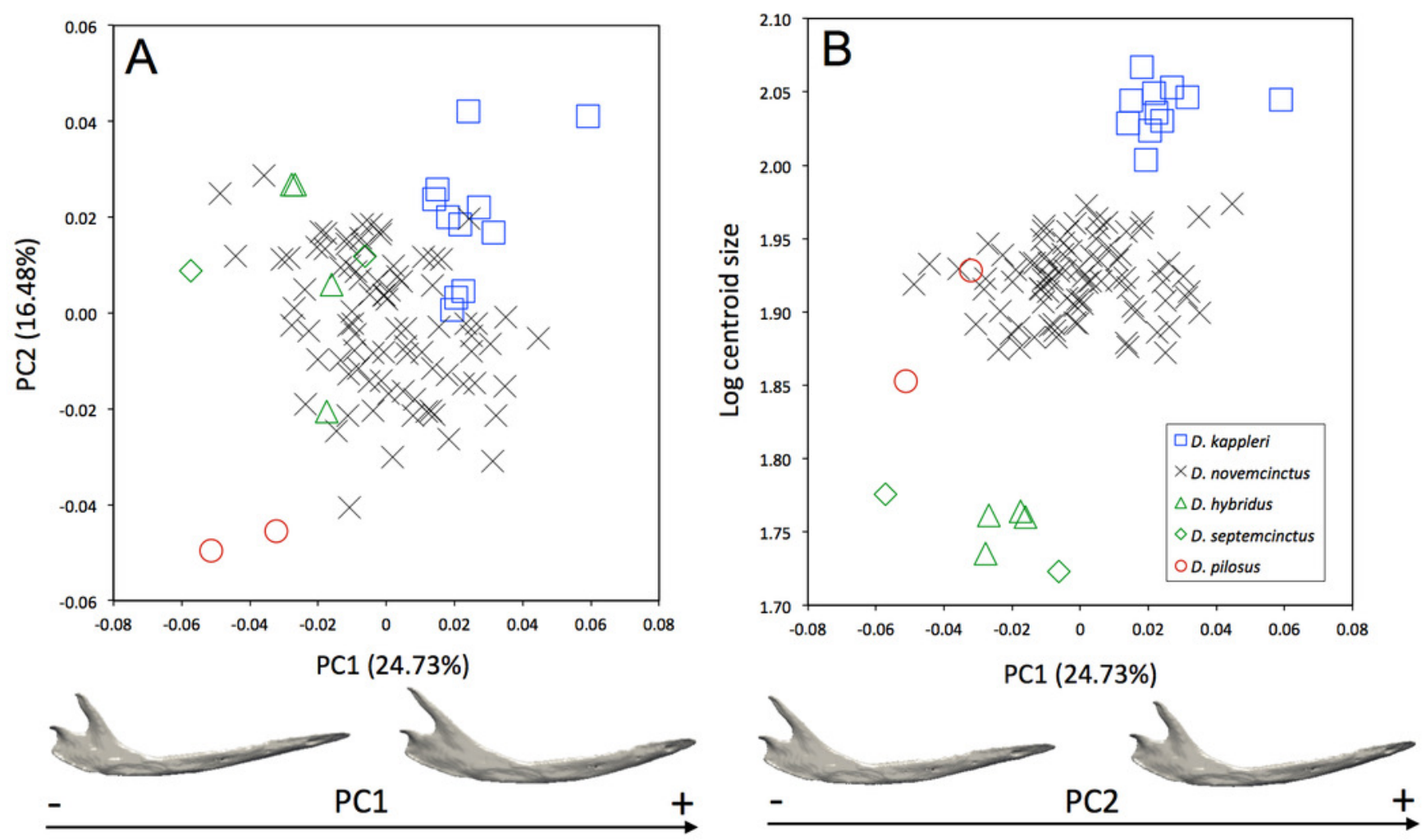


\section{Figure 4}

Figure 4

(A) Principal component analysis (PC1 vs PC2) and associated patterns of morphological transformation for crania of five Dasypus species. (B) Regression of the first principal component on the logarithm of the centroid size $\left(R^{2}=0.50 ; p<0.001\right)$. Symbols: blue squares, $D$. kappleri; black crosses, $D$. novemcinctus; green triangles, $D$. hybridus; green diamonds, $D$. septemcinctus; red circles, D. pilosus.
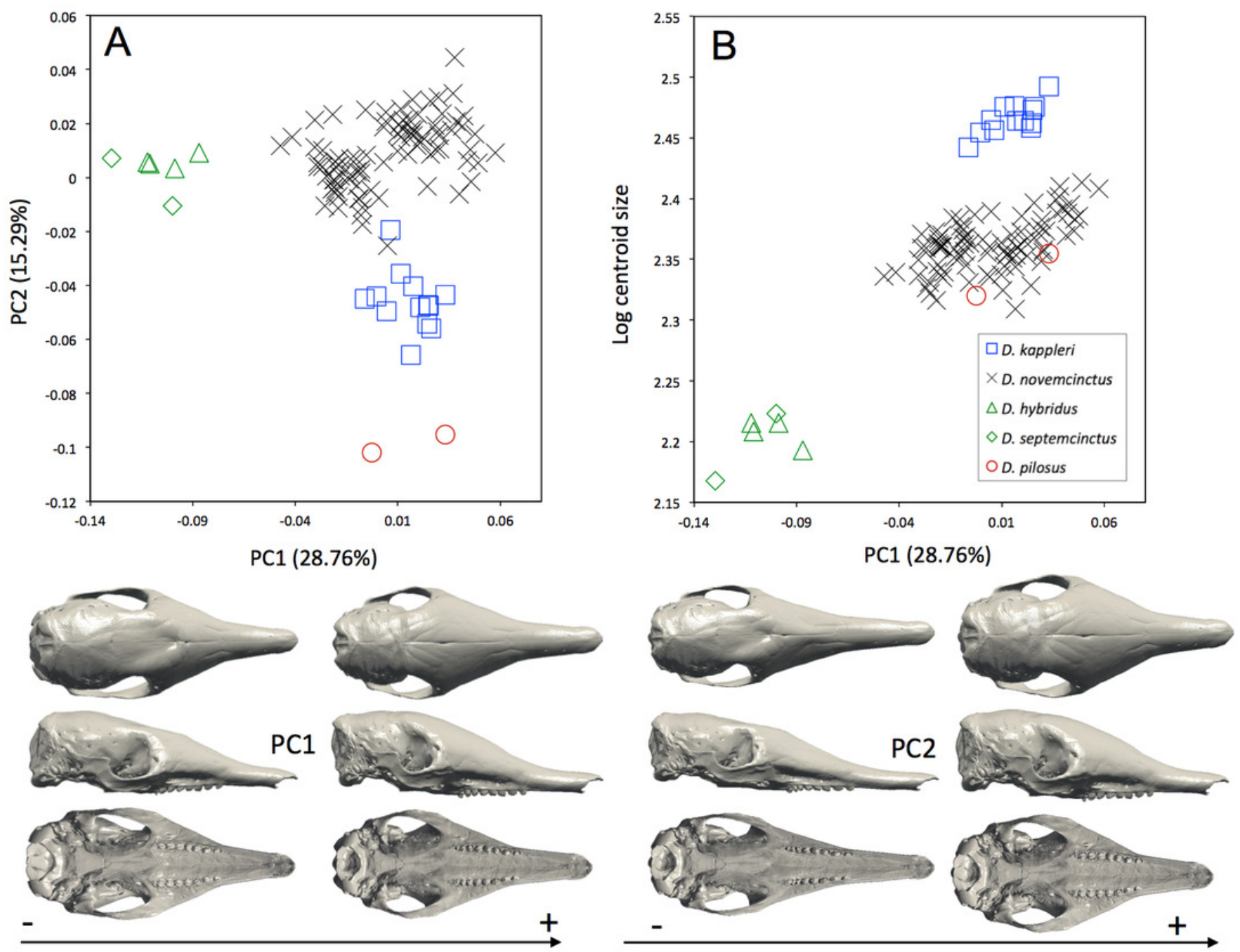


\section{Figure 5}

Figure 5

(A) Principal component analysis (PC1 vs PC2) and associated patterns of morphological transformation for mandibles of Dasypus novemcinctus. (B) Regression of the first principal component on the logarithm of the centroid size $\left(R^{2}=0,035 ; p=0.03\right)$. Symbols: green diamonds, Bolivia; green triangle, Brazil (solid green triangles are for specimens from Amapa); green circles, Paraguay; green crosses, Peru; green squares, Uruguay; green bars, Venezuela; blue diamonds, Belize; blue "plus", Guatemala; blue bars, Honduras; blue squares, Mexico; blue crosses, Nicaragua; blue triangles, USA; blue circles, Costa Rica; black triangles, Colombia; black crosses, Ecuador; black stars, Panama; orange squares, French Guiana; orange crosses, Guyana; orange circles, Suriname.
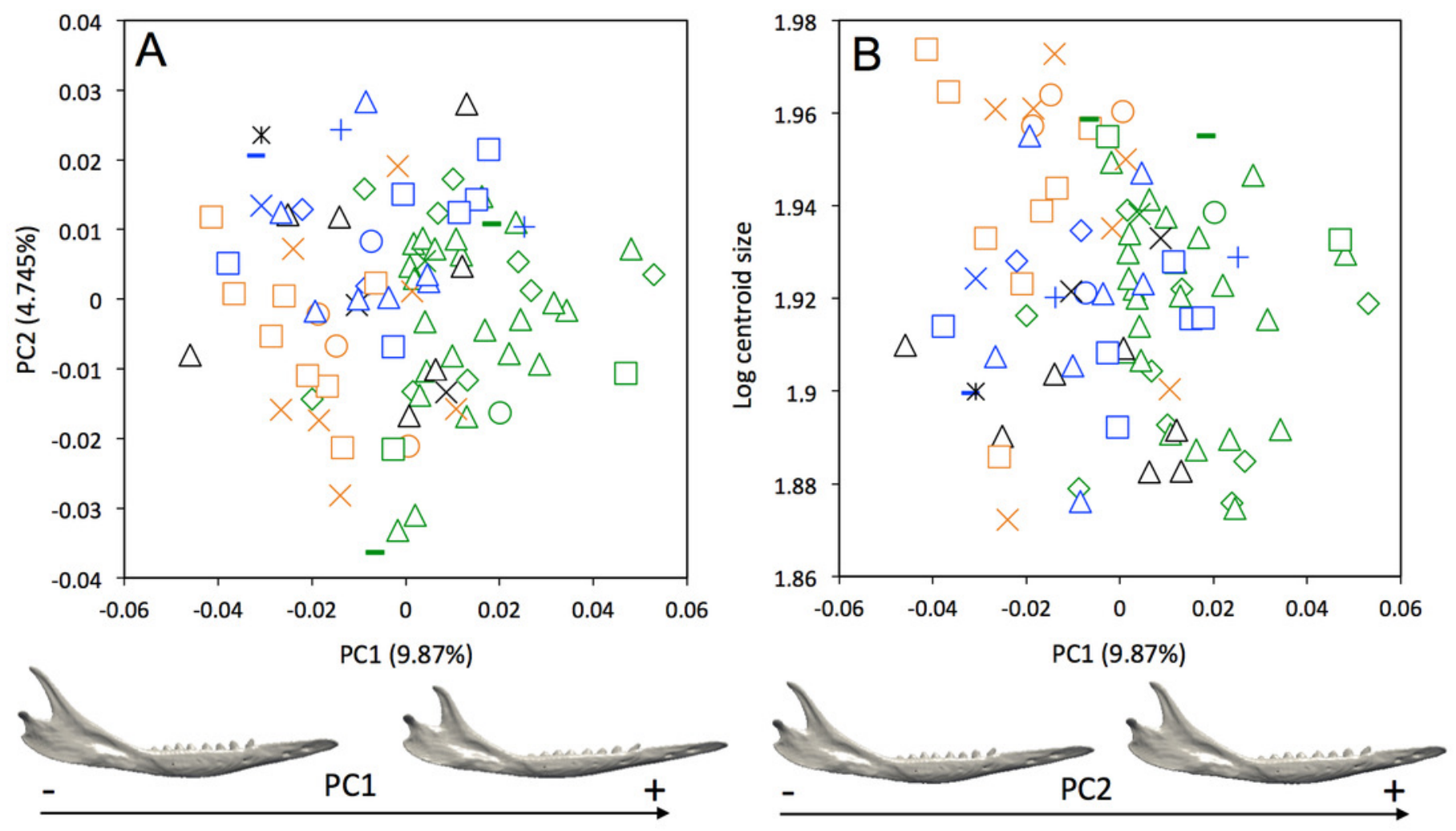


\section{Figure 6}

Figure 6

Principal component analysis (A, PC1 vs PC2; B, PC3 vs PC4) and associate patterns of morphological transformation for crania of Dasypus novemcinctus. Symbols: green diamonds, Bolivia; green triangle, Brazil (solid green triangles are for specimens from Amapa); green circles, Paraguay; green crosses, Peru; green squares, Uruguay; green bars, Venezuela; blue diamonds, Belize; blue "plus", Guatemala; blue bars, Honduras; Blue squares, Mexico; blue crosses, Nicaragua; blue triangles, USA; blue circles, Costa Rica; black triangles, Colombia; black crosses, Ecuador; orange squares, French Guiana; orange crosses, Guyana; orange circles, Suriname. 

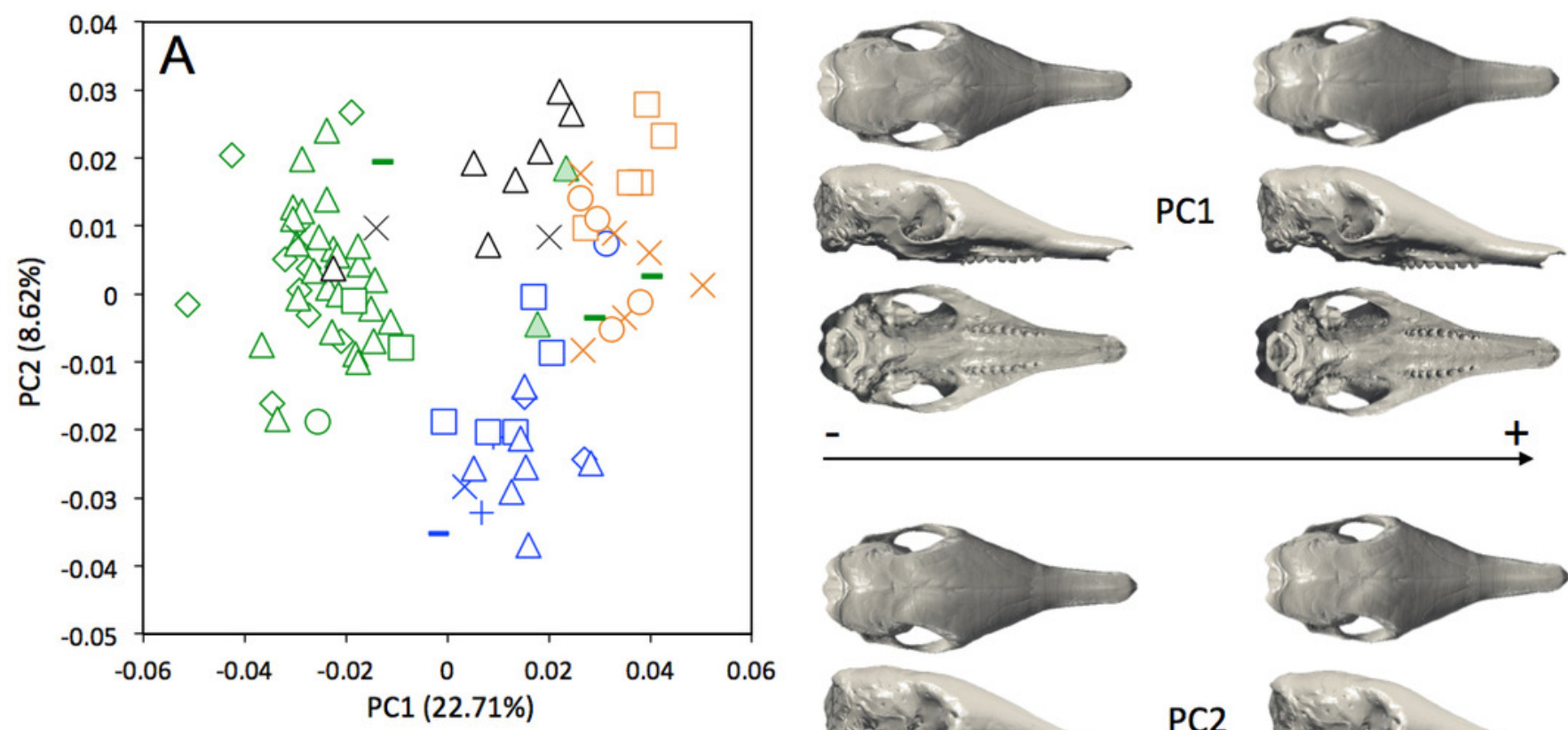

-

PC1
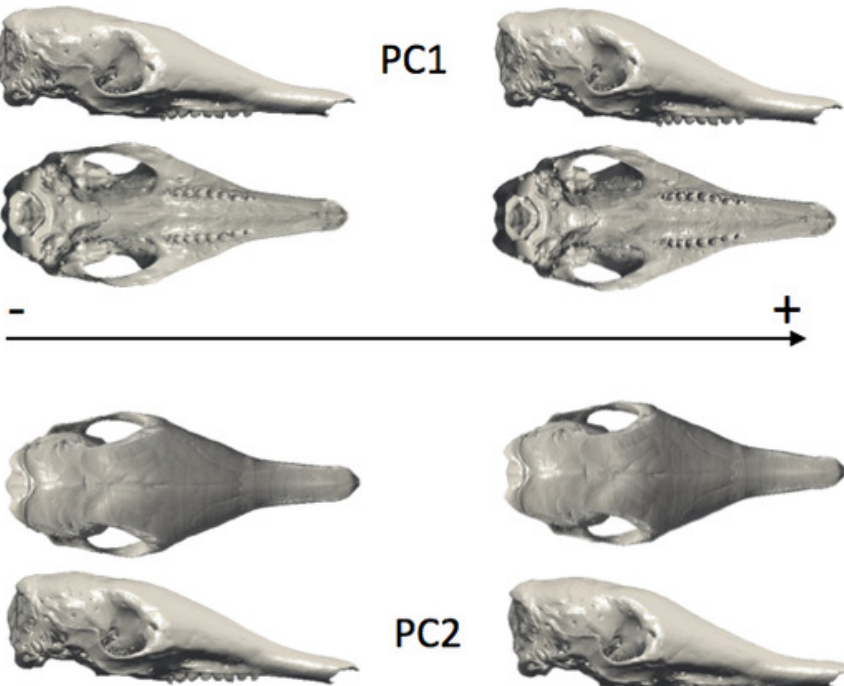

PC2
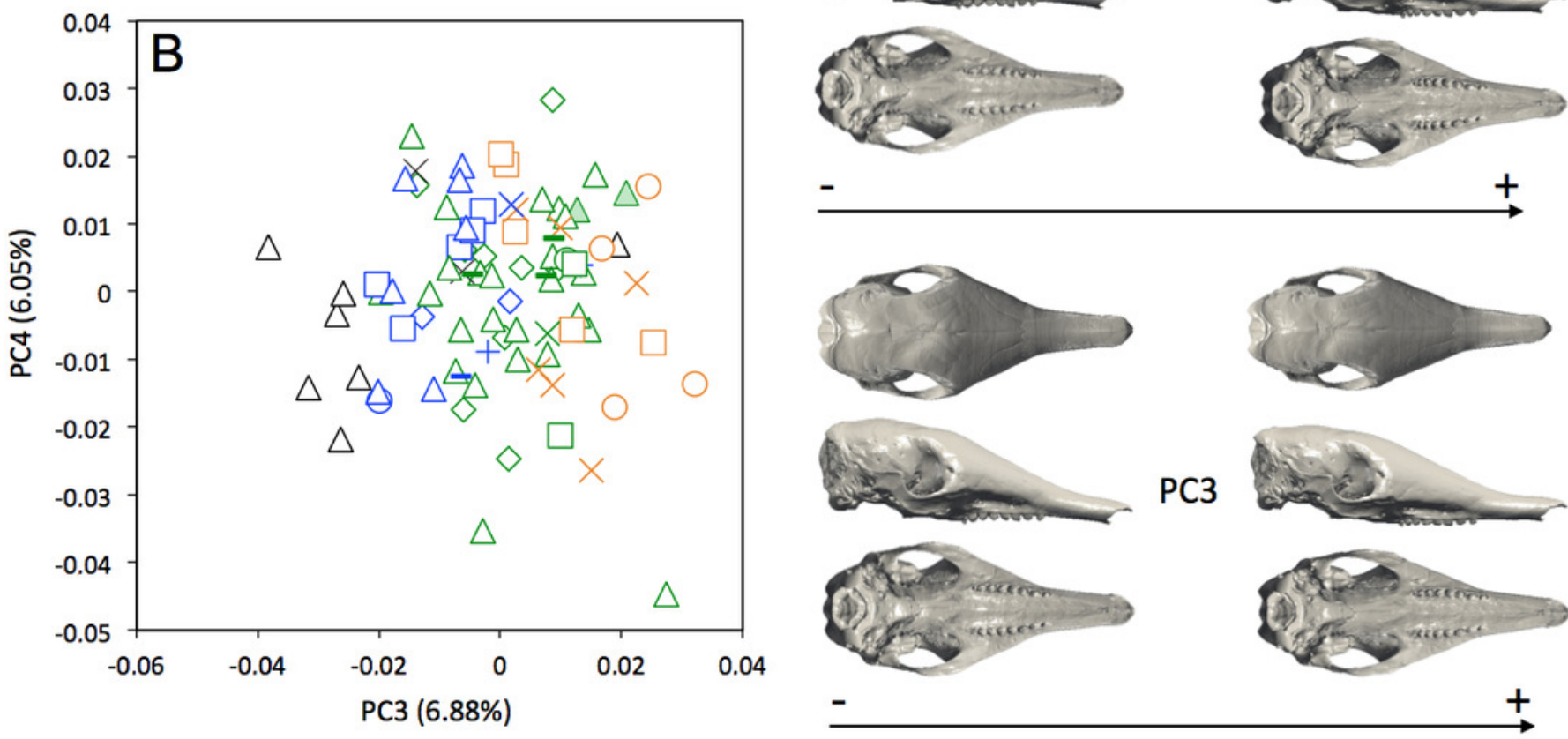


\section{Figure 7}

Figure 7

Regression of the first cranial principal component (Dasypus novemcinctus) on the logarithm of the centroid size $\left(R^{2}=0.15 ; p<0.001\right)$. Symbols: green diamonds, Bolivia; green triangle, Brazil (solid green triangles are for specimens from Amapa); green circles, Paraguay; green crosses, Peru; green squares, Uruguay; green bars, Venezuela; blue diamonds, Belize; blue "plus", Guatemala; blue bars, Honduras; blue squares, Mexico; blue crosses, Nicaragua; blue triangles, USA; blue circles, Costa Rica; black triangles, Colombia; black crosses, Ecuador; orange squares, French Guiana; orange crosses, Guyana; orange circles, Suriname. 

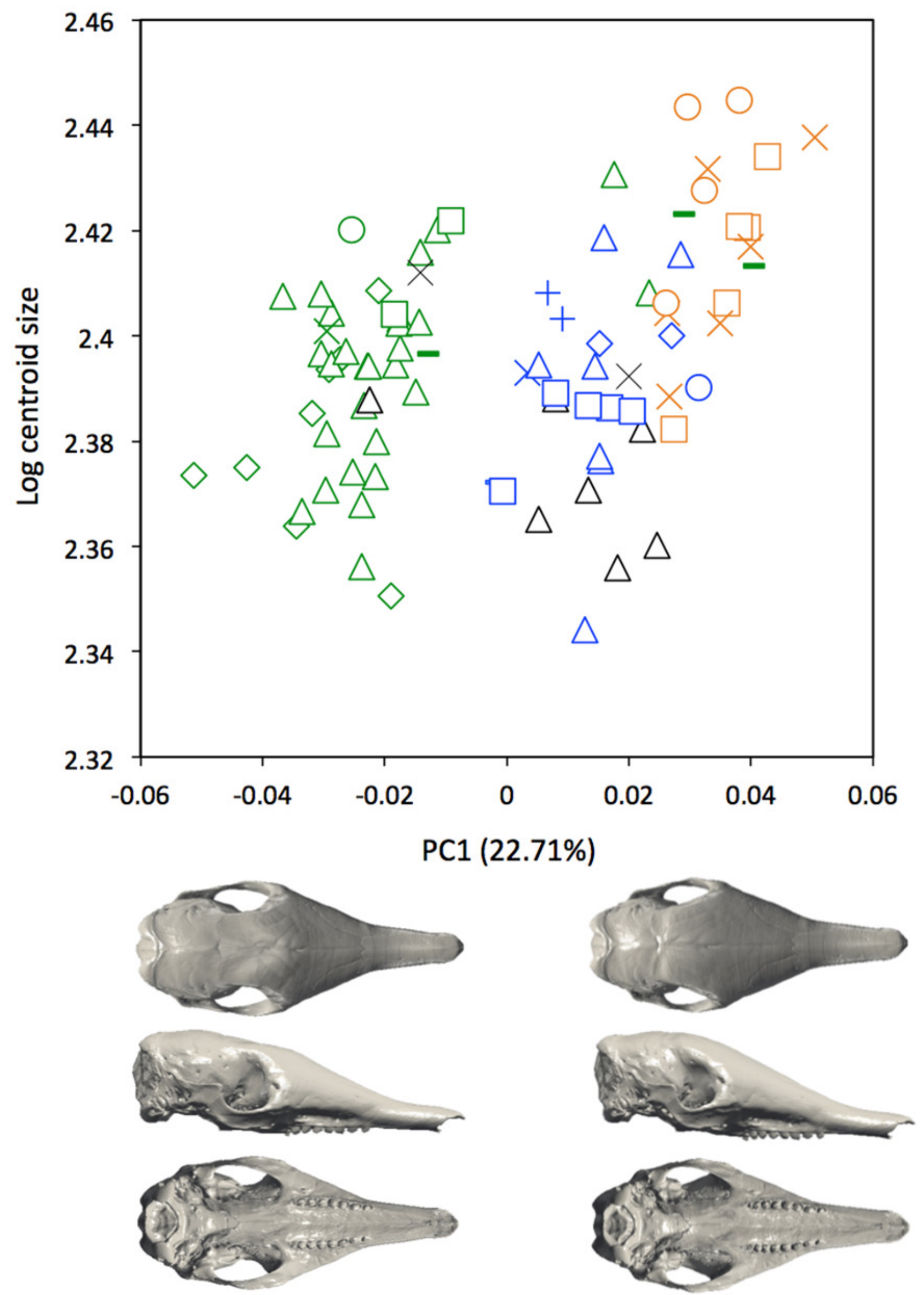


\section{Figure 8}

Figure 8

Linear Discriminant Analysis (LDA) performed on cranial shape coordinates of Dasypus novemcinctus. Symbols: green diamonds, Bolivia; green triangle, Brazil (solid green triangles are for specimens from Amapa); green circles, Paraguay; green crosses, Peru; green squares, Uruguay; green bars, Venezuela; blue diamonds, Belize; blue "plus", Guatemala; blue bars, Honduras; Blue squares, Mexico; blue crosses, Nicaragua; blue triangles, USA; black triangles, Colombia; black circles, Costa Rica; black crosses, Ecuador; orange squares, French Guiana; orange crosses, Guyana; orange circles, Suriname.
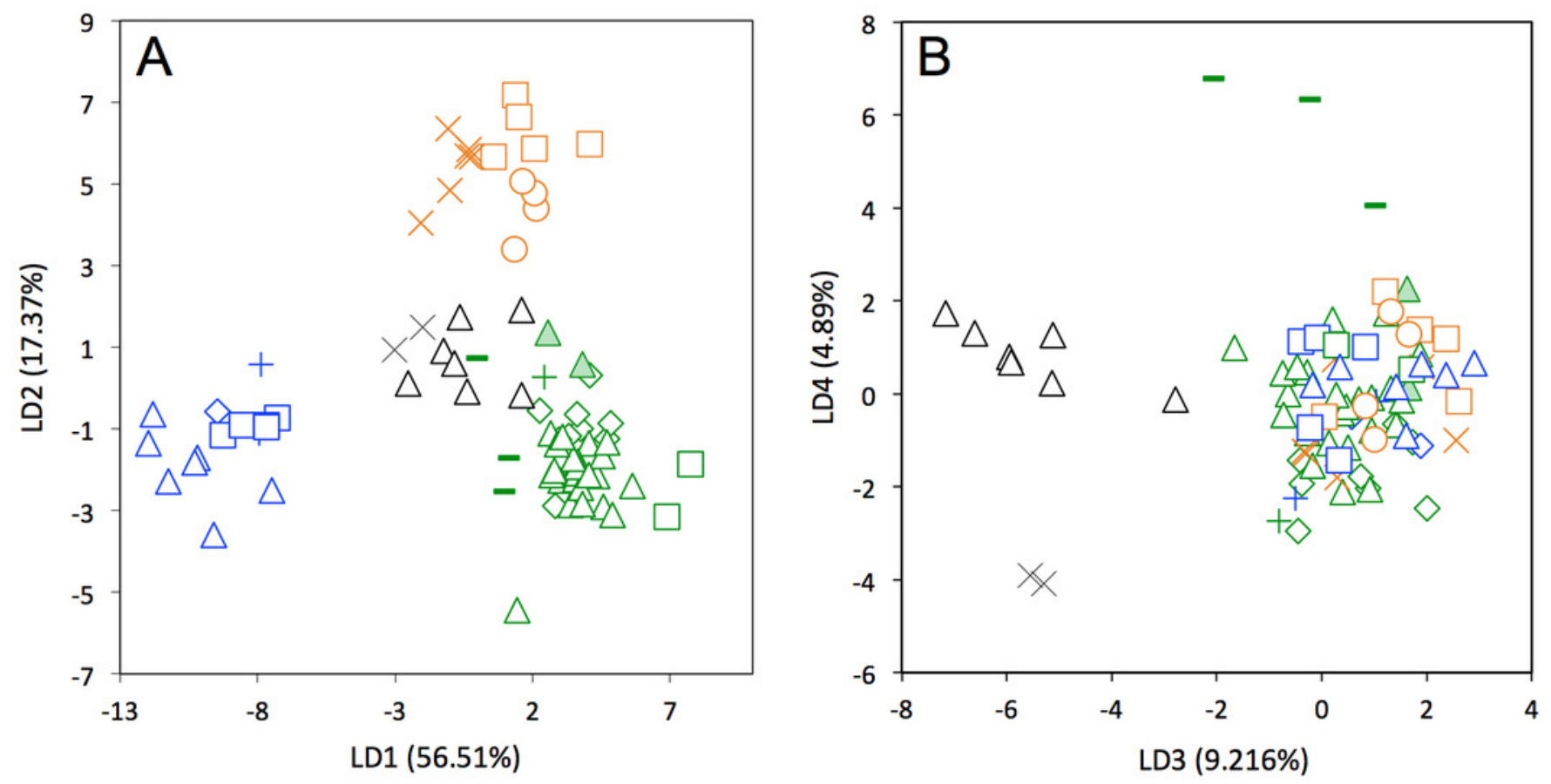


\section{Figure 9}

Figure 9

Summary map showing the geographical distribution of nine-banded armadillo specimens investigated in this study and their attribution to one of the four main morphotypes defined in this study: black, Central group; blue, Northern group; green, Southern group; orange, Guianan group. Specimens lacking precise geographical information (other than country of origin) are indicated with a square.

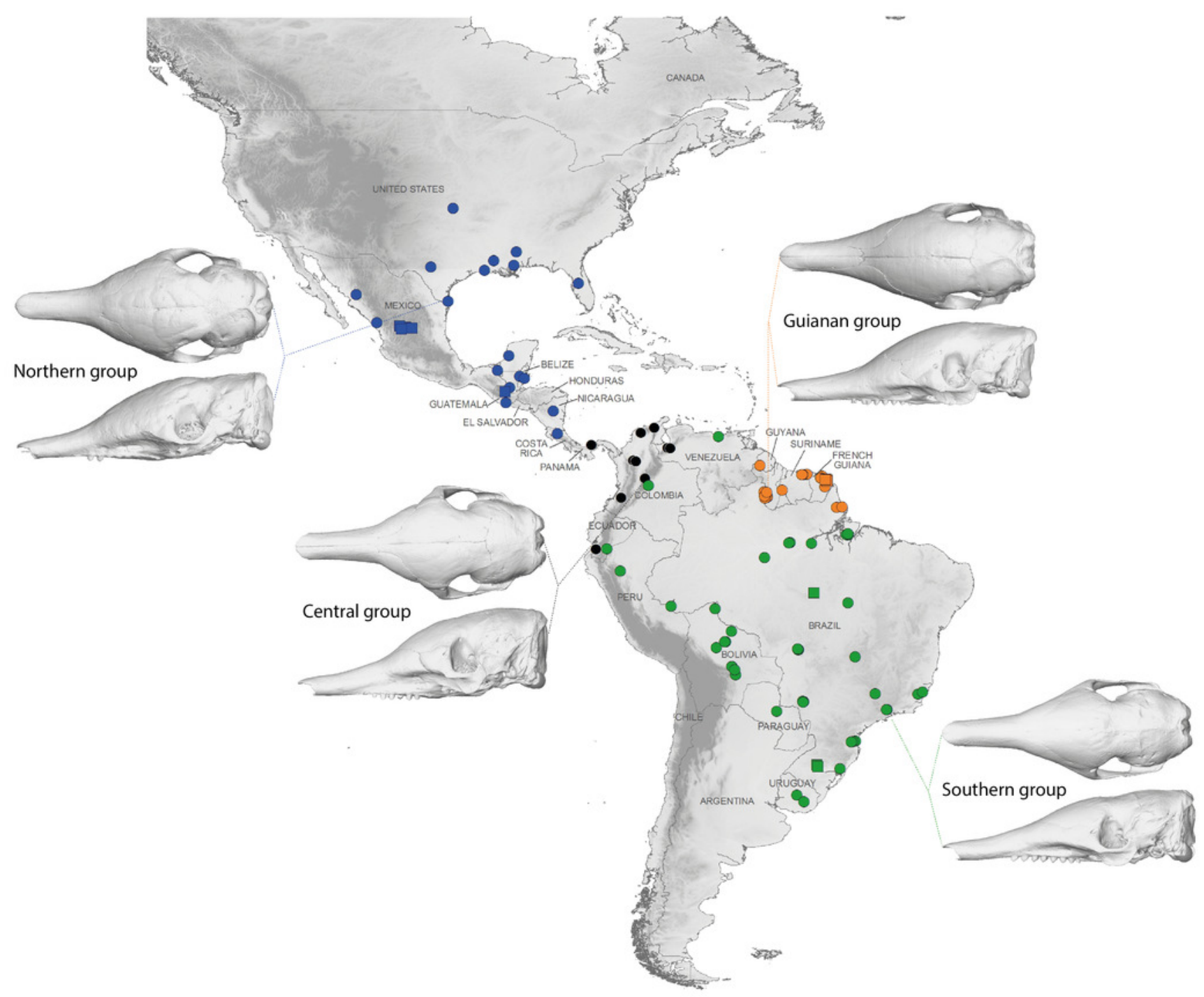




\section{Table 1 (on next page)}

Table 1

Definitions of the landmarks used on the mandible 


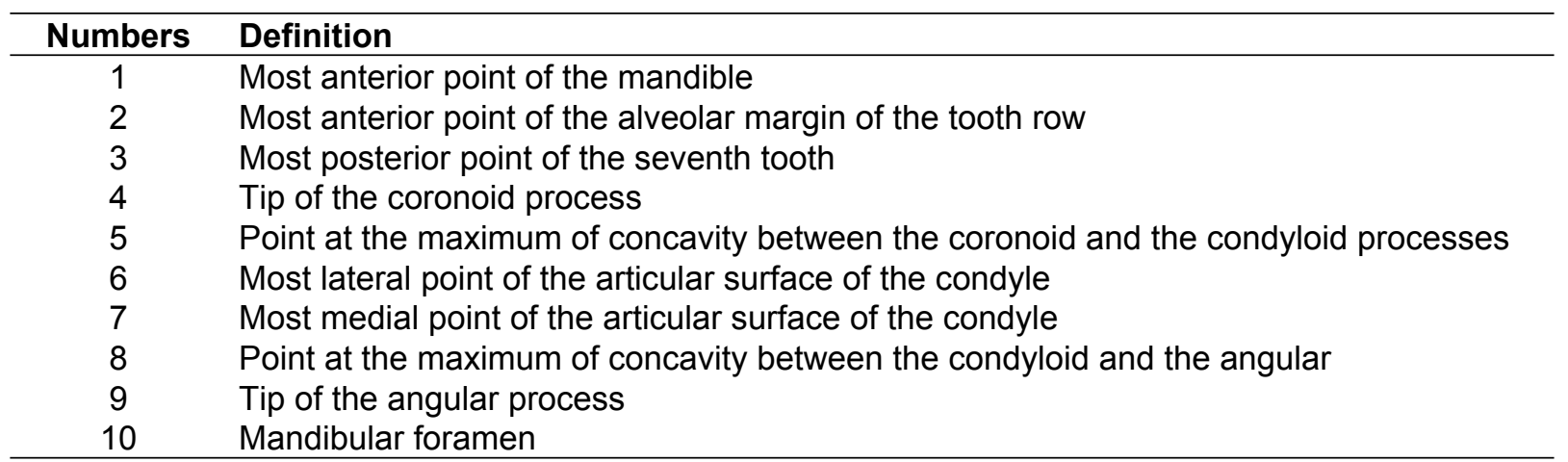

1 


\section{Table 2 (on next page)}

Table 2

Definitions of the landmarks used on the cranium. Landmarks indicated with a star were not used in the intraspecific comparisons. 


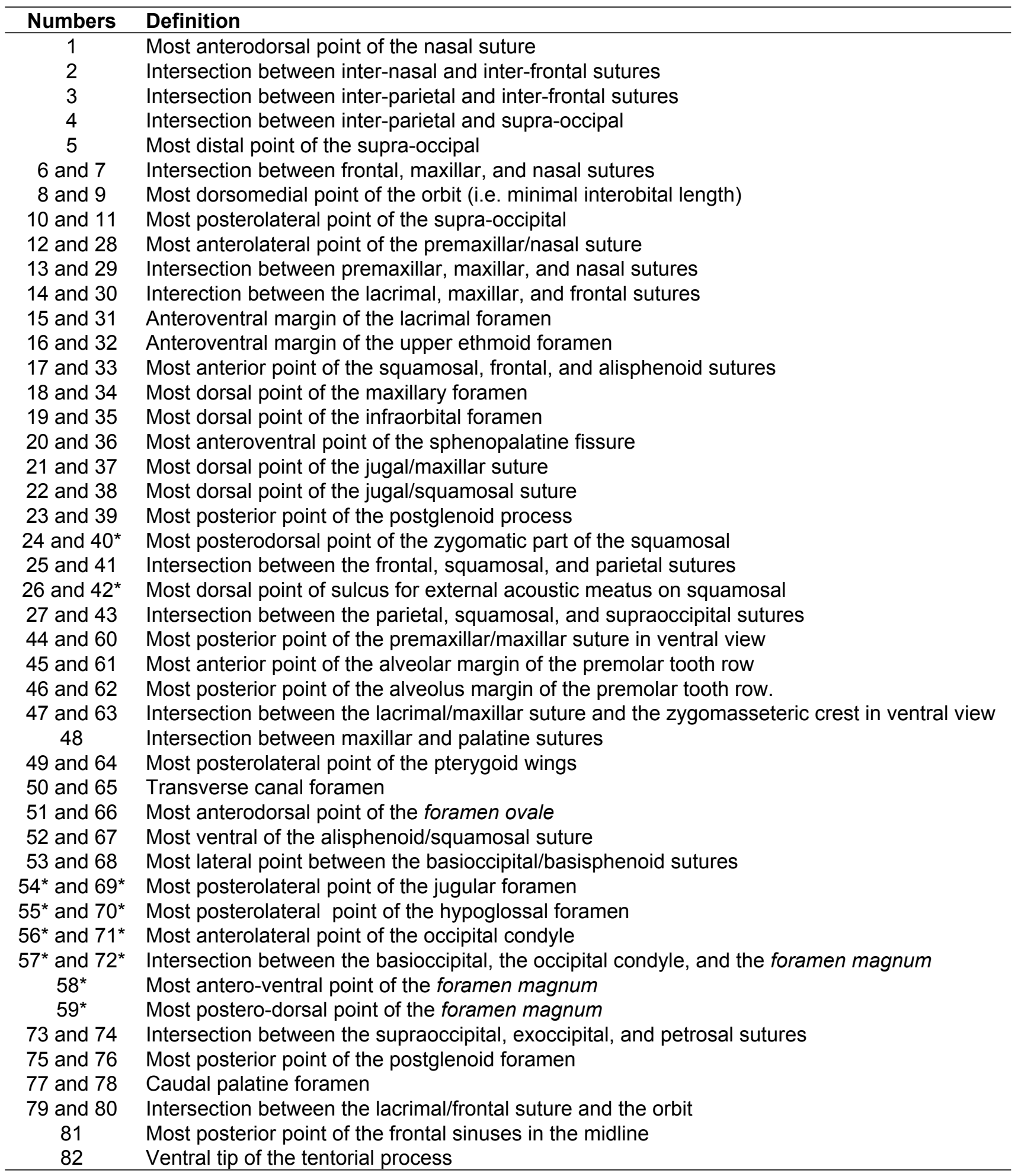

